Document downloaded from:

http://hdl.handle.net/10251/122890

This paper must be cited as:

Salvador, FJ.; Carreres, M.; De La Morena, J.; Martínez-Miracle-Muñoz, EC. (2018). Computational assessment of temperature variations through calibrated orifices subjected to high pressure drops: application to diesel injection nozzles.. Energy Conversion and Management. 171:438-451. https://doi.org/10.1016/j.enconman.2018.05.102

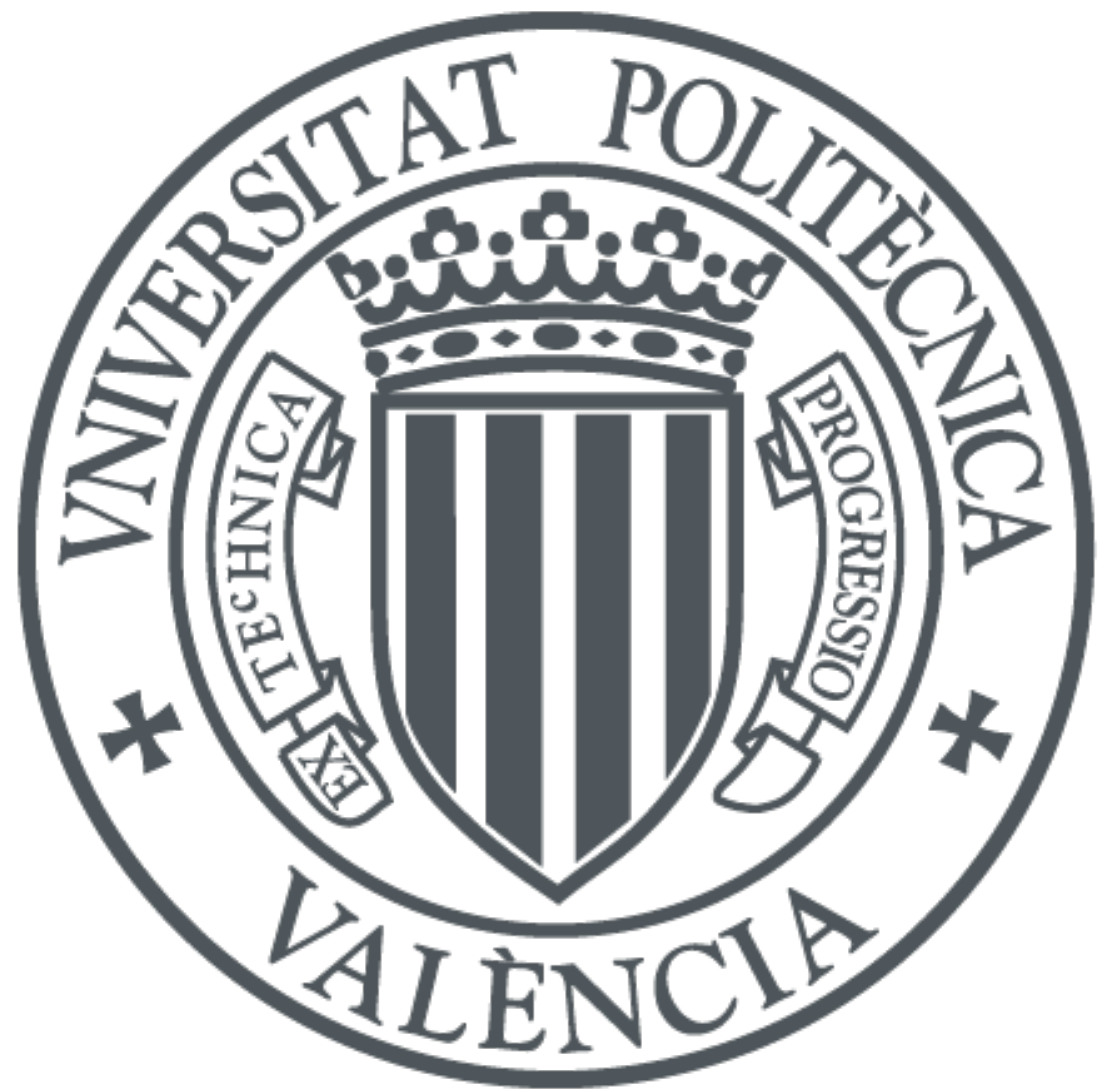

The final publication is available at

https://doi.org/10.1016/j.enconman.2018.05.102

Copyright Elsevier

Additional Information 


\title{
COMPUTATIONAL ASSESSMENT OF TEMPERATURE VARIATIONS THROUGH CALIBRATED ORIFICES SUBJECTED TO HIGH PRESSURE DROPS: APLICATION TO DIESEL INJECTION NOZZLES.
}

Salvador, F.J. (*), Carreres, M., De la Morena, J., Martínez-Miracle, E.

CMT-Motores Térmicos, Universitat Politècnica de València

Camino de Vera s/n, E-46022, Valencia, Spain.

(*) Corresponding author:

Dr. F. Javier Salvador, fsalvado@ mot.upv.es

CMT-Motores Térmicos, Universitat Politècnica de València

Camino de Vera s/n, E-46022, Valencia, Spain.

Telephone: +34-963879659

FAX: $+34-963877659$

\begin{abstract}
This paper conducts an investigation on the temperature variations experienced by the fuel when it expands through the calibrated orifices of a commercial diesel injector. Experimental results of the temperature change across a calibrated orifice upon expansion, extracted from a previous work, are compared to the temperature predicted by computational fluid dynamic simulations under the assumption of adiabatic flow, with no heat transfer to the surroundings. The comparison points out that the simulations are able to predict the thermal effects taking place inside the orifice. Once the model is validated,
\end{abstract}


the flow morphology is analyzed to explain the trends observed in the fuel temperature change across the orifice depending on the operating conditions. Two opposed effects take place inside the orifice: on the one hand, the flow is cooled in the orifice core due to depressurization; on the other hand, the fuel is importantly heated near the walls due to viscous friction. As expected, the net effect on the outlet temperature mainly depends on the orifice discharge coefficient, governed by the orifice geometry and the flow regime (Reynolds number) induced by the injection conditions. Next, the analysis is extended to a diesel nozzle, considering that the higher pressure drops achieved in it are expected to induce even more important thermal effects. The two opposed effects also take place inside the orifice. Even though their net effect is similar, the separate effect of each phenomenon is greater, leading to differences that could be relevant for the atomization and spray formation processes. Additionally, the flow pattern shows a non-uniform distribution of the flow inside the nozzle influencing the results from the thermal point of view.

KEYWORDS: thermal effects, injector, modelling, compressibility, fuel properties

\section{NOMENCLATURE}

$A_{M} \quad$ Thermal conductivity coefficients matrix

$a_{i j} \quad$ Elements of the thermal conductivity coefficients matrix

$A_{o} \quad$ Geometrical area

$C_{d} \quad$ Discharge coefficient

$c_{p} \quad$ Constant-pressure fuel specific heat

D Specific heat coefficients matrix 
$D_{i} \quad$ Geometrical nozzle inlet diameter

$D_{o} \quad$ Geometrical nozzle outlet diameter

$d_{i j} \quad$ Elements of the specific heat coefficients matrix

$h \quad$ Local enthalpy

$h_{o} \quad$ Local stagnation enthalpy

$k_{t} \quad$ Fuel thermal conductivity

$k$-factor $\quad$ Nozzle conicity factor; $k-$ factor $=\frac{D_{i}[\mu m]-D_{0}[\mu m]}{10}$

$m_{f} \quad$ Mass flow

p Pressure

$p_{d w} \quad$ Downstream or discharge pressure

$p_{u p} \quad$ Upstream or injection pressure

$S_{E} \quad$ Energy source term

$\vec{S}_{M} \quad$ Body forces

$T \quad$ Temperature

$t \quad$ Time

$\vec{u} \quad$ Local velocity vector

$u_{\text {out }} \quad$ Outlet nozzle orifice velocity

OZ orifice Calibrated orifice used for the investigation

\section{Greek Symbols}

$\Delta P \quad$ Pressure drop, $\Delta P=p_{u p}-p_{d w}$

$\beta \quad$ Volumetric thermal expansion coefficient; $\beta=-\frac{1}{\rho}\left(\frac{\partial \rho}{\partial T}\right)_{p}$

$\mu_{0} \quad$ Fuel dynamic viscosity at $0.1 \mathrm{MPa}$ pressure

$\mu_{f} \quad$ Fuel dynamic viscosity 


$\begin{array}{ll}\rho & \text { Local density } \\ \rho_{f} & \text { Fuel density } \\ \tau & \text { Tensor field } \\ v_{f} & \text { Fuel kinematic viscosity }\end{array}$

\section{Introduction}

In diesel engines, the fuel-air mixing process dominates the combustion process and emissions formation. This mixing process is directly linked to the interaction between the in-cylinder air motion, driving the design of the intake ports and valve profiles as investigated by Nigro et al. [1], and the fuel injection system, as thoroughly reviewed by Mohan et al. [2]. For this reason, research has been recently focused on the influence of both the injector geometry and the injection conditions on the atomization and mixing processes. From the point of view of the geometry, Som et al. [3] computationally analyzed the effect of the nozzle orifice diameters, conicity and inlet radii on the spray features, linking them to combustion and emission characteristics. Sayin et al. [4] investigated the influence of the injector hole number on the engine performance and emissions, whereas Gavaises [5] and the authors [6] tried to gain insight on the role of cavitation on the fuel spray mixing capabilities through an analysis of the effect of the hydro erosion. As a result, for instance, new nozzle concepts have been suggested by the authors in the form of elliptical orifices [7] or convergent-divergent orifices [8], whereas other researchers analyzed the possibility of including twin-hole nozzles in diesel injection systems [9], reporting their lower penetration when compared to the equivalent single hole nozzles. As far as the injection conditions are concerned, Wang et al. [10] analyzed the effect of increasing the injection pressure on the soot formation, whereas Gumus et al. [11] linked this property to the engine emissions. As a result, the injection pressures used by OEMs have been progressively growing up to even $300 \mathrm{MPa}$. 
The flow within diesel injectors has traditionally been regarded to as isothermal. Giannadakis et al. [12] studied the flow patterns through a cylindrical hole and a tapered hole nozzle with this approach, comparing simulations with constant fuel properties with simulations that considered variations in the fuel properties with the local pressure. They observed a gain in accuracy in the latter case, but omitted the effect of the temperature variations in the simulations. Som et al. also conducted numerical investigations with the isothermal flow assumption [13], [3], reporting the influence of the fuel properties on the diesel injection problem. They compared the internal flow and spray features when injecting fluids with the reference properties of both diesel and biodiesel, reporting that biodiesel would need to be injected at a higher temperature than diesel in order to exhibit similar atomization characteristics. More recently, Sun et al. [14] investigated the effects of nozzle geometry and injection pressure on the cavitation formation and spray characteristics, but also neglected the effect of the fuel temperature changes in the problem.

Nevertheless, as a result of the progressive growth in the fuel injection pressures, some thermal effects inside the injector that were not especially relevant in the past are now gaining importance. This is the case of the flow along the injector control orifices or the nozzle, where the strong pressure gradients driving the flow result in important temperature changes due to two main effects: on the one hand, the rapid depressurization of the fuel, which may significantly reduce the fuel temperature in the orifice core; on the other hand, an important viscous heating at the wall of the orifices induced by friction due to the high velocity gradients. This behavior drives for the need to introduce also the pressure and temperature dependence of the fluid properties into the solver, due to their impact on the fluid-dynamic field [15]. 
Therefore, some works started treating the flow inside the injector as adiabatic. In the 1D modelling field, Catania et al. [16] were the first authors to introduce this assumption. Later on, the authors incorporated it to their models of complete diesel injectors [17]. As far as CFD modelling is concerned, Shi et al. [18] included the effect of the strong pressure gradients through the nozzle on fuel temperature and consequently fuel density and viscosity, coupling the CFD code to a 1D injector model. They compared the accuracy of this approach with the constant properties one for a honed and an un-honed nozzle. Theodorakakos et al. [19] also investigated the thermal effects in nozzle holes subjected to high pressure drops, paying more attention to the temperature field along the nozzle. Analyzing the two aforementioned effects on the flow, they reported that, depending on the nozzle discharge coefficient and the injection conditions, the flow in average could be heated at the outlet or even subcooled. Next, Strotos et al. [20] extended this work by analyzing the transient stages of the injection through the inclusion of the needle movement. However, even though this work offers a comparison of computational results against $0 \mathrm{D}$ theoretical models with the adiabatic flow assumption, none of them were compared with experimental results. Later, the authors [21] tried to assess the hypothesis of adiabatic flow in diesel injectors by experimentally measuring the temperature change across calibrated orifices subjected to an isenthalpic expansion in different conditions and comparing it to the theoretical one.

In the present paper, an investigation of the thermal effects found in different characteristic orifices of a diesel injector subjected to significant expansions is carried out. First, the dimensions of the orifices and the physical properties of the fuel used are determined experimentally, allowing to introduce pressure and temperature dependent properties in the CFD solver. Later on, the results obtained by simulations are validated (both in terms of mass flow rate and predicted temperature change) against experimental 
measurements, previously performed on one of the calibrated orifices inside the injector control volume, as described in [21]. Results for the OZ calibrated orifice are analyzed by determining the conditions that lead to either heating or subcooling the flow. Also, special attention is given to the flow morphology in order to justify the reasons for the reported trends and evaluate the impact of the observed temperature distribution on the fuel properties.

Finally, once the methodology is validated on the calibrated orifice, it is applied also to the orifices of a diesel injector nozzle. Although the results in this case cannot be validated against experimental temperature values, due to the high difficulty to measure the temperature upstream and downstream of the nozzle orifices in an accurate way, there are two reasons why exploring such a geometry can be of interest. First, the orifices of the diesel nozzle are subjected to a larger pressure drop than the calibrated orifices (in the range of up to $250 \mathrm{MPa}$ for current production injectors), so the thermal effects inside these orifices can be more relevant. Additionally, changes in the temperature characteristics inside the nozzle orifices can significantly affect the spray atomization and evaporation characteristics, with a direct impact on the combustion process. Thus, providing a reasonable estimation of the fuel temperature at the nozzle outlet, which is the aim of the current investigation, can be of great relevance for other works in fuel injection and combustion simulations.

The paper is divided in 6 sections. Section 2 deals with the experimental techniques used for the study, including the geometrical characterization of the orifices used for the CFD study and the fuel properties determination. Next, Section 3 describes the computational model and the setup used for the simulations performed on the basis of Ansys CFX with a customized fuel. The used mesh and the simulation cases are also dealt with in this section. Section 4 shows the validation of the model against the experimental results from 
a previous work by the authors [21] and a discussion of the relevance of the thermal effects depending on the studied condition. Section 5 analyzes the potential temperature effects appearing inside the nozzle orifices, by means of a simulation campaign on a realistic nozzle geometry. Finally, Section 6 gathers the main conclusions of the study.

\section{Experimental facilities}

Next section briefly describes the techniques and resources that have been used in order to perform the experimental measurements.

\subsection{Geometric characterization of the calibrated orifice.}

The calculation of the modelled temperature due to viscous effects or the cooling caused by decompression is highly influenced and highly dependent on the involved geometry. Determining the geometry of the injector control volume with precision is of key importance to obtain results and validate the theoretical CFD model correctly. The chosen geometry for the thermal experimental characterization and modelling corresponds to the calibrated inlet orifice $(\mathrm{OZ})$ of a control volume from a commercial Bosch CRI 2.20 injector. In Figure 1, the piece containing the control volume and the OZ orifice is depicted at the right hand side. The control volume assembled on the injector is plotted at the left hand side. The role of this orifice in the way the injector works does not fall within the scope of this work and further explanations on this regard are given in [22]. 

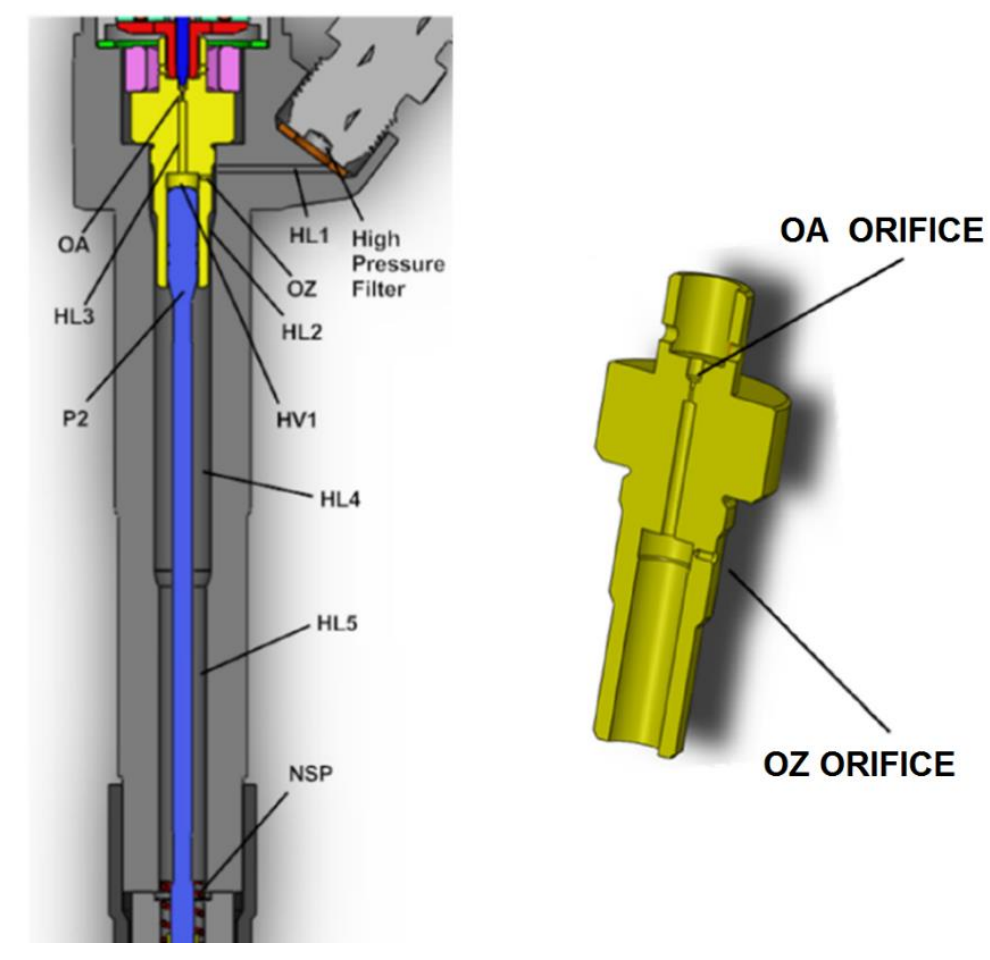

Figure 1. Control volume piece containing the calibrated orifice (OZ) in Bosch 2.20 injector.

In order to fully describe its volume, a silicone mold from the interior cavity has been obtained and visualized in a scanning electron microscope (SEM). This methodology is thoroughly described in [23]. This technique provides a high resolution picture of the topography of the injector's inlet orifice. The dimensions based on this image are measured by an auxiliary CAD software. The deviation over the mean value has been reported to be below $2 \%$ [24]. The most critical part of the whole orifice is the throat, where pressure and velocity gradients are significantly strong. Taking this into account, several measurements of the radius of this section have been gauged over three points along its length (inlet point, middle point and outlet point).

In Figure 2, some pictures of the silicone molds obtained with the SEM to define the OZ orifice geometry are shown. Additionally, Figure 3 depicts the geometry of the orifice 
obtained through the metrology analysis from the silicone molds. All sections inside the $\mathrm{OZ}$ orifice are assumed to be circular.
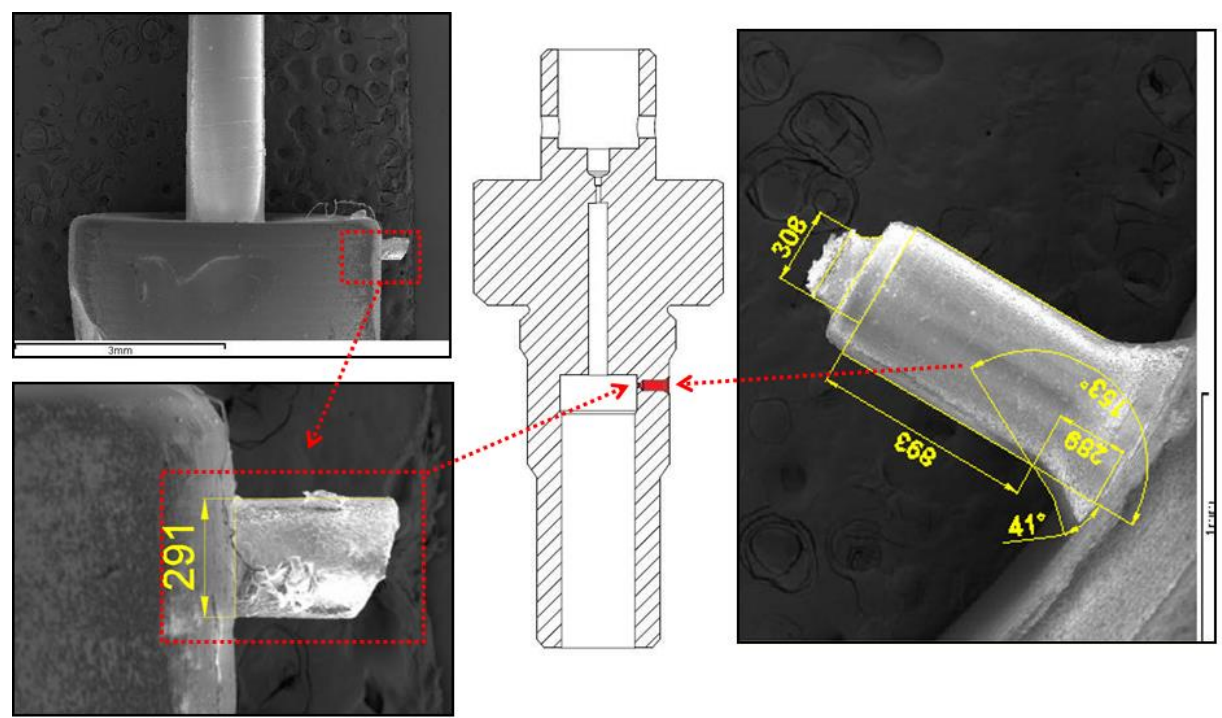

Figure 2. Geometrical characterization of the calibrated orifice (OZ) with silicone molds and SEM visualization.

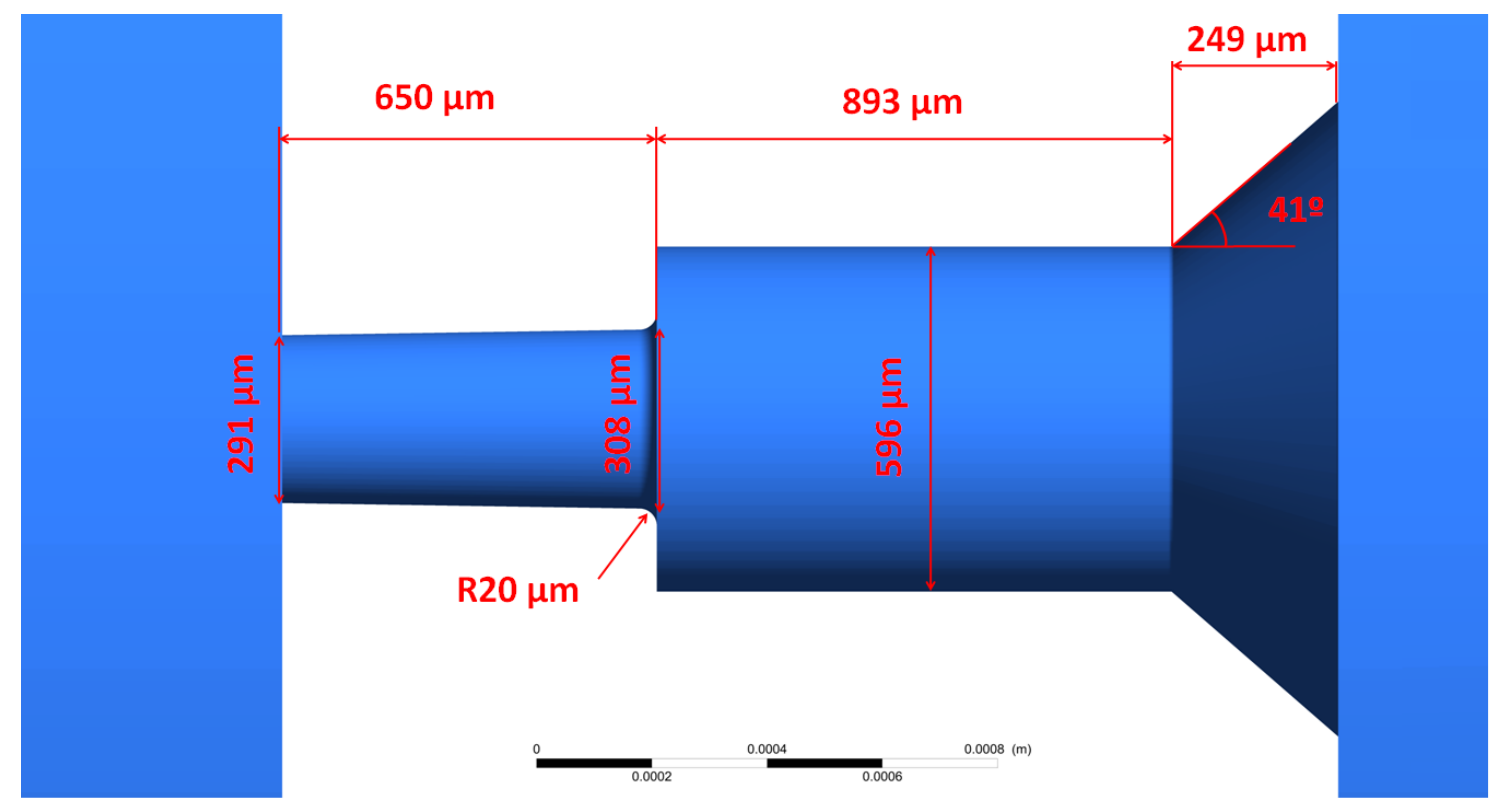

Figure 3. Dimensional characteristics of the calibrated orifice (OZ).

As it can be noted, the most restrictive part of the $\mathrm{OZ}$ orifice from the point of view of the flow (where the diameter is smallest) has a conical shape: $308 \mu \mathrm{m}$ at the inlet vs 291 
$\mu \mathrm{m}$ at the outlet. In this part of the orifice, a conicity factor ( $k$-factor), can be defined to quantify the level of conicity. Using the Bosch definition, it may be calculated by means of equation (1):

$k-$ factor $=\frac{D_{i}[\mu m]-D_{0}[\mu m]}{10}$

where $D_{i}$ and $D_{o}$ are, in the current case, $308 \mu \mathrm{m}$ and $291 \mu \mathrm{m}$, respectively. With these values, the $k$-factor equals 1.7. Considering this value, and according to previous results reported by the authors, cavitation phenomenon inside the orifice is not expected ([25][28]). This result will be confirmed later by the experimental and computational results.

\subsection{Geometric characterization for the nozzle orifices.}

As stated in the introduction, the current paper will explore not only the previously presented $\mathrm{OZ}$ calibrated orifice in the control volume, but also the orifices of a diesel injector nozzle. For this purpose, the geometry of a 7-holes nozzle extracted from a commercial common-rail Bosch solenoid injector has been characterized using the previously cited silicone molds technique. Figure 4 shows a schematic of the nozzle geometry, together with some sample images obtained from the post-processing of the silicone molds for some of the key orifice dimensions. For the subsequent 3D modeling of the injector flow, the orifice is constructed using the average values from the seven holes. This represents an inlet diameter of $0.143 \mathrm{~mm}$, an outlet diameter of $0.124 \mathrm{~mm}$, an inlet rounding radius of $0.029 \mathrm{~mm}$ and a total length of $0.715 \mathrm{~mm}$. Again, the shape of the difference sections inside the nozzle orifices is assumed to be circular. 


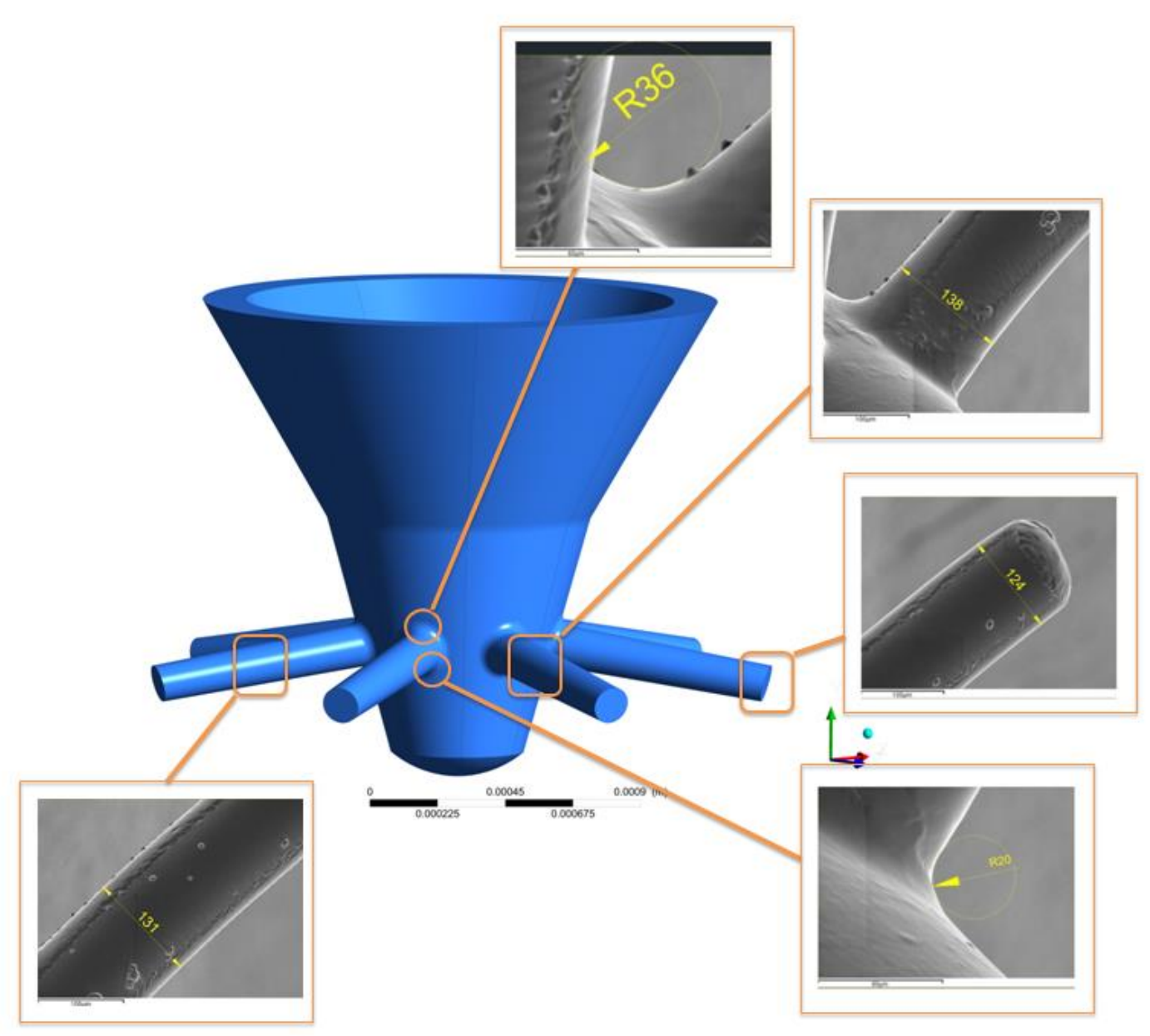

Figure 4. Dimensional characterization of the nozzle orifices.

\subsection{Fuel properties determination.}

From the point of view of the CFD modelling, the correct definition of the functions that govern the behavior of the fuel with respect to the principal thermodynamic variables, namely pressure and temperature, will affect the result of the CFD simulation ([29]). These functions will also determine the range of conditions in which the code can be validated according to the experimental data. In an attempt to be as accurate as possible, fuel density, viscosity, specific heat and thermal conductivity have been set as variable properties of pressure and temperature. The numerical adjustment of these features follows empirical data and the methods employed to define them are described below. Therefore, as a first step, the main properties of the fuel have been measured under a wide 
range of pressure and temperature conditions. The considered fluid consists of a European standard winter diesel fuel. The density was characterized by the authors at atmospheric pressure as a function of temperature (ranging from $273 \mathrm{~K}$ to $373 \mathrm{~K}$ ) using a standard hydrometer, taking into account the considerations stated by the ASTMD1298 procedure [30] (including those corresponding to the calibration procedure [31]). The accuracy of the hydrometer was determined to be $\pm 5 \times 10^{-4} \mathrm{~kg} / \mathrm{m}^{3}$.

In order to establish the variations of the fuel density with the pressure, speed of sound measurements were also performed at different pressures (up to $20 \mathrm{MPa}$ ) and temperatures (from $300 \mathrm{~K}$ to $353 \mathrm{~K}$ ) following the methodology established in [31]. The maximum deviations reported during the calibration of the facility were $1.24 \%$ over the expected values.

The kinematic viscosity of the fuel was determined at atmospheric pressure for a wide range of temperatures (from $263 \mathrm{~K}$ to $373 \mathrm{~K}$ ) by means of a commercial Cannon-Fenske viscometer. This device, a type of capillary viscometer, was used following the procedure specified in the ASTMD445 standard [32] in order to obtain an empirical expression for the viscosity as a function of temperature at atmospheric pressure. In accordance to this standard, the tolerance of this device was determined to be $\pm 0.36 \%$ with $95 \%$ certainty. A comparison of the measured values for reference substances during the calibration led to deviations lower than $3 \%$ in all cases. The viscosity values at high pressure were estimated from the expression introduced by Kouzel [33].

In order to quantify these trends and dispose of suitable data for the computational model implementation, the experimental data coming from the density and viscosity characterization tests have been fitted to mathematical expressions as a function of 
temperature and pressure. These expressions showed a high coefficient of determination $\left(\mathrm{R}^{2}=0.99\right)$ in all cases [31]. In the case of the density, the expression obtained was:

$\rho_{f}=826.5-1.0217(T-298)+1.251 \cdot 10^{-3}(T-298)^{2}+0.6035(p-0.1)-$

$8.265 \cdot 10^{-4}(p-0.1)^{2}+1.441 \cdot 10^{-3}(T-298)(p-0.1)$

where $\rho_{f}$ is the density (in $\mathrm{kg} / \mathrm{m}^{3}$ ) whereas $p$ and $T$ are the fuel pressure and temperature (in MPa and K), respectively.

On the other hand, the viscosity approach leads to an exponential expression as derived from the Kouzel expression [33]:

$\mu_{f}=10^{-3} \mu_{0} \cdot 10^{\left[\left(-1.48+5.86 \mu_{0}^{0.181}\right) \cdot\left(\frac{p-0.1013}{1000}\right)\right]}$

Where $\mu_{f}$ is the dynamic viscosity at a given pressure and temperature, whereas $\mu_{0}$ is the dynamic viscosity of the fluid at atmospheric pressure $(0.1 \mathrm{MPa})$ and at a given temperature:

$\mu_{0}=3.2158 \cdot \mathrm{e}^{[-0.0263(T-298)]}$

This dynamic viscosity is obtained by multiplying the measured density and the corresponding kinematic viscosity. Both $\mu_{f}$ and $\mu_{0}$ have units of $\mathrm{Pa} \cdot \mathrm{s}$. As in Equation (2), $p$ and $T$ are the fuel pressure and temperature (in MPa and $\mathrm{K}$ ), respectively.

The resulting values of density and dynamic viscosity as a function of pressure and temperature are plotted in Figure 5 for the winter Diesel fuel used both for the experiments and the calculations. 

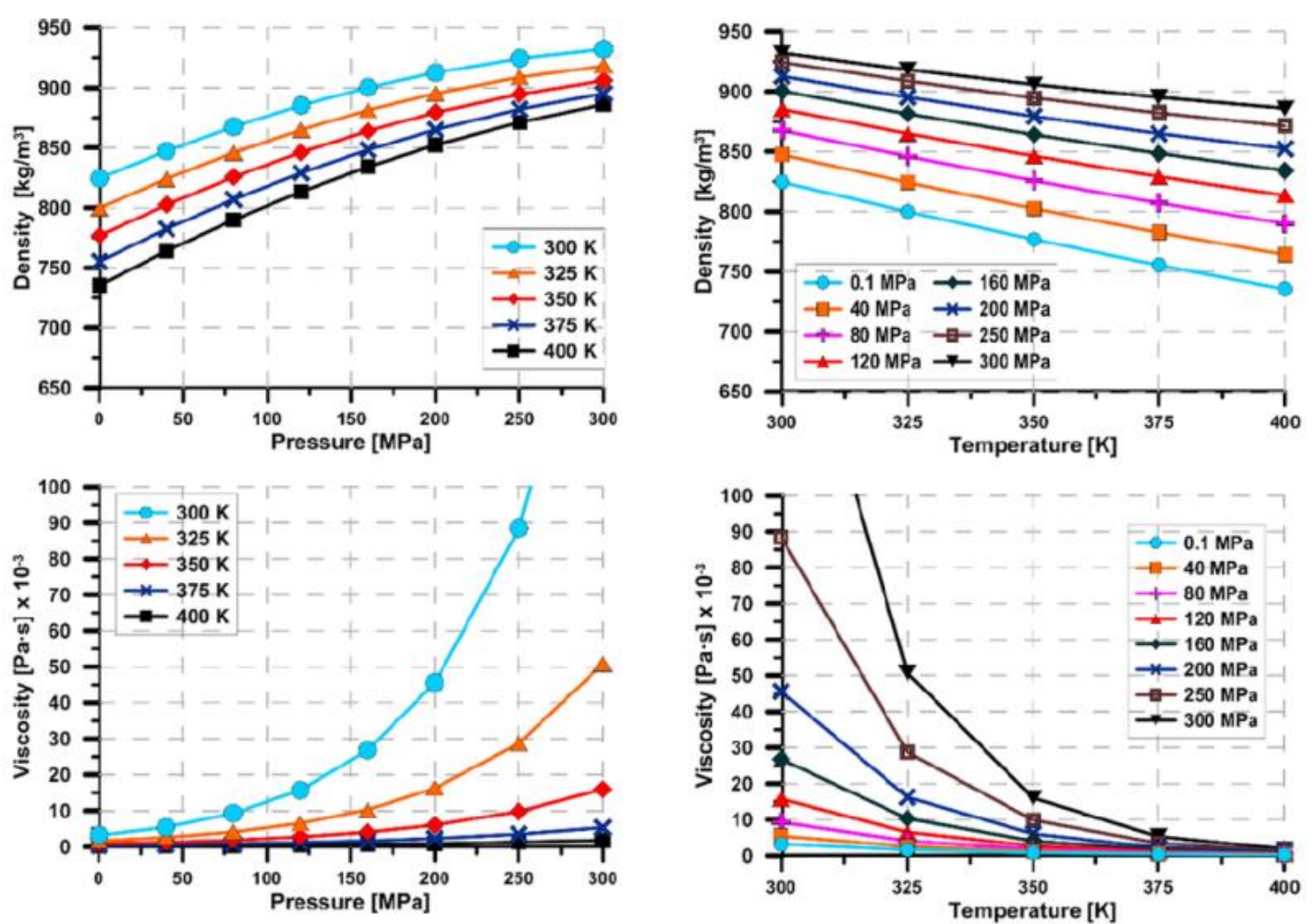

Figure 5. Winter diesel density and viscosity as a function of pressure and temperature.

Additional fuel properties related to heat transfer effects, such as thermal conductivity $\left(k_{t}\right)$ and specific heat $\left(c_{p}\right)$ have been obtained from Kolev [34] for a similar diesel fuel. As in the case of the fuel density, experimental results have been fitted to polynomial expressions. In this case, their coefficients have been compiled on a matrix. As it happened for the density and viscosity, the characterization of these properties is valid over a wide range of pressures and temperatures, ranging from 0 to $250 \mathrm{MPa}$ in the case of the pressure and $273 \mathrm{~K}$ to $393 \mathrm{~K}$ in the case of temperature. Equation (5) deals with the specific heat polynomial expression as a function of pressure and temperature:

$c_{p}=\sum_{i=1}^{5}\left(\sum_{j=1}^{3} d_{i j} \cdot T^{j-1}\right)\left(\frac{p}{10^{5}}\right)^{i-1}$

where $p$ is in $\mathrm{Pa}$ and the $d_{i j}$ coefficients are the elements of a matrix $(D)$ defined as: 


$$
D_{5 \times 3}=\left(\begin{array}{ccc}
-977.16186 & 14.025100 & -0.01374 \\
2.22361 e-4 & -1.62143 e-4 & 2.23214 e-9 \\
-1.96181 e-9 & 2.03748 e-7 & -1.78571 e-14 \\
4.15000 e-14 & -7.54100 e-11 & 4.03897 e-28 \\
-3.48714 e-18 & 1.00688 e-14 & -1.47911 e-31
\end{array}\right)
$$

As far as the thermal conductivity $\left(k_{t}\right)$ is concerned, as in the case of the specific heat, it is defined by the following polynomial expression:

$k_{t}=\sum_{i=1}^{3}\left(\sum_{j=1}^{3} a_{i j} \cdot T^{j-1}\right)(p)^{i-1}$

where $p$ is in Pa and the coefficients $a_{i j}$ are the elements of a matrix $\left(A_{M}\right)$ defined as:

$$
A_{3 \times 3}=\left(\begin{array}{ccc}
0.13924 & 3.78253 e-5 & -2.89732 e-7 \\
6.27425 e-11 & 6.08052 e-13 & 3.64777 e-16 \\
-1.38756 e-19 & -2.57608 e-22 & -2.70893 e-24
\end{array}\right)
$$

All the polynomial fits reported in this section correspond to measurements for a Diesel fuel that are experimentally verified for pressures between $0.1 \mathrm{MPa}$ and $250 \mathrm{MPa}$ and temperatures between $273 \mathrm{~K}$ and $393 \mathrm{~K}$. Even though the speed of sound measurements used as a basis for the determination of the fuel density at high pressure were only performed from 300 to $353 \mathrm{~K}$, the known linear behavior of the density of the diesel fuels with the temperature does not compromise the validity of these fits in the aforementioned range.

\section{Numerical approach.}

The main aspects related to the modeling work performed are described next.

\subsection{Computational model and governing equations.}

CFD simulations have been performed using the CFX commercial software developed by ANSYS Inc v17.0, which has been customized using appropriate user functions related to the thermodynamic fuel properties introduced in section 2.3. The software solves the 
conservation equations based on a Finite Volume Methodology, which has proven to be optimal for similar CFD applications [35]. The k-epsilon model for turbulence flow in his RNG form ([36], [37]) was used because of the better results it has provided for similar studies compared to those found by the authors with its standard version [6], [7], [38]. The near-wall approach function has been defined using scalable-wall functions [39].

The common Navier-Stokes equations are numerically solved, including the continuity, momentum and energy equations. The energy equation is of particular interest and is described as:

$\frac{\partial\left(\rho h_{o}\right)}{\partial t}-\frac{\partial p}{\partial t}+\nabla \cdot\left(\rho \vec{u} h_{o}\right)=\nabla \cdot\left(k_{t} \nabla T\right)+\nabla \cdot(\vec{u} \cdot \tau)+\vec{u} \cdot \vec{S}_{M}+S_{E}$

where $S_{E}$ is the energy source term, $k_{t}$ is the thermal conductivity and $h_{o}$ is the stagnation enthalpy, related to the specific enthalpy $h(T, p)$ through:

$h_{o}=h+\frac{1}{2} u^{2}$

The general formulation for the specific entalphy $h$ as a function of $T$ and $p$ is:

$d h=\left(\frac{\partial h}{\partial T}\right)_{p} d T+\left(\frac{\partial h}{\partial p}\right)_{T} d p$

Using the heat capacity under constant pressure $\left(c_{p}\right)$, Eq. 13 can be rewritten as:

$d h=c_{p} \cdot d T+\frac{1}{\rho}\left[1+\frac{T}{\rho}\left(\frac{\partial \rho}{\partial T}\right)_{p}\right] d p$

which can also be written as a function of the volumetric thermal expansion $(\beta)$ :

$d h=c_{p} \cdot d T+\frac{1-\beta \cdot T}{\rho} d p$

where $\beta$ is defined as: 
$\beta=-\frac{1}{\rho}\left(\frac{\partial \rho}{\partial T}\right)_{p}$

Note that the second term of the right hand side of Eqs. (14) and (15) would be null for an ideal gas (for which $\beta \cdot T=1$ ), but cannot be neglected for a liquid.

In each calculation, values of $\rho(p, T), \mu(p, T), k_{t}(p, T)$ and $c_{p}(p, T)$ are updated using the available polynomial fits (recall section 3.2) with the latest calculated values of $p$ and $T$ after each iteration.

\subsection{Mesh description, simulation cases and model setup.}

In the case of the calibrated $\mathrm{OZ}$ orifice, due to the symmetry of the domain, axisymmetric simulations have been performed using a wedge geometry of $5^{\circ}$. The orifice dimensions included in Figure 3 have been used in order to build the mesh. Figure 5 shows the complete 3D computational domain with a detail of the mesh structure in the orifice. Constant pressure boundary conditions are selected for both the inlet and the outlet boundary conditions. The particular values of these boundary conditions come from the experimental campaign performed for this same orifice in a previous publication by the authors [21]. The fuel inlet temperature is set as $293 \mathrm{~K}$ for all cases. Fuel mass flow and the mean temperature at the orifice outlet are the most important results predicted by the simulations and they have been compared to the experimental values and analyzed in the next section. A non-slip boundary condition is used for the walls. 

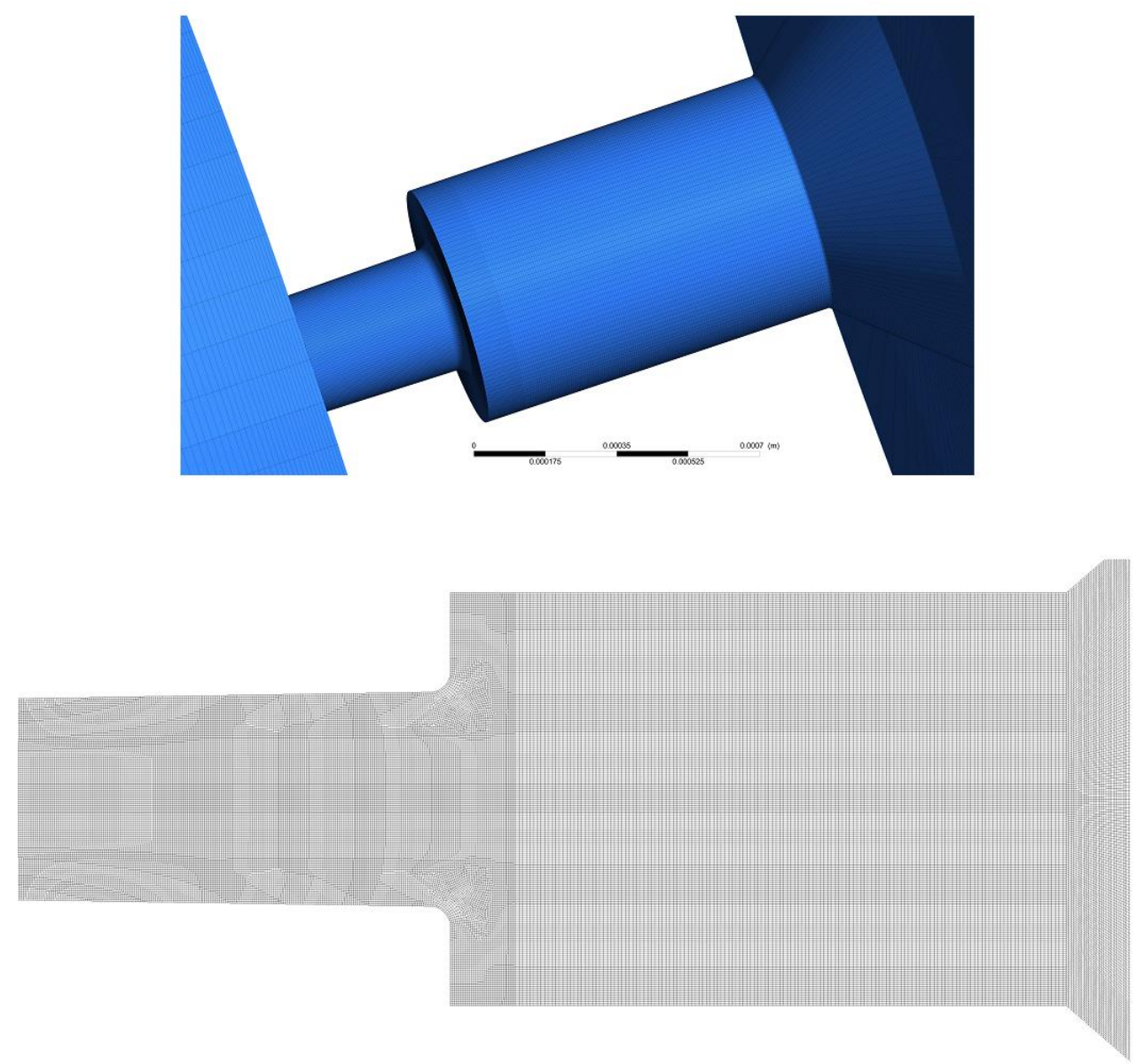

Figure 5. Mesh used for the simulations.

For the nozzle and OZ orifice meshes, similar meshing strategy and characteristic cell sizes to those employed in previous 3D-CFD nozzle flow simulations [28] have been used. A mesh sensitivity study including GCI calculations and Richardson extrapolation [40], [41] was performed in order to ensure a small numerical error due to the meshes. From a practical point of view and aiming to future applications, the nozzle is the most interesting case and given the complexity of the geometry, its meshing process must be carefully carried out. Figure 6 shows the convergence of the nozzle mass flow rate as a function of the number of cells for the nozzle mesh in the case of $130 \mathrm{MPa}$ of injection pressure. 


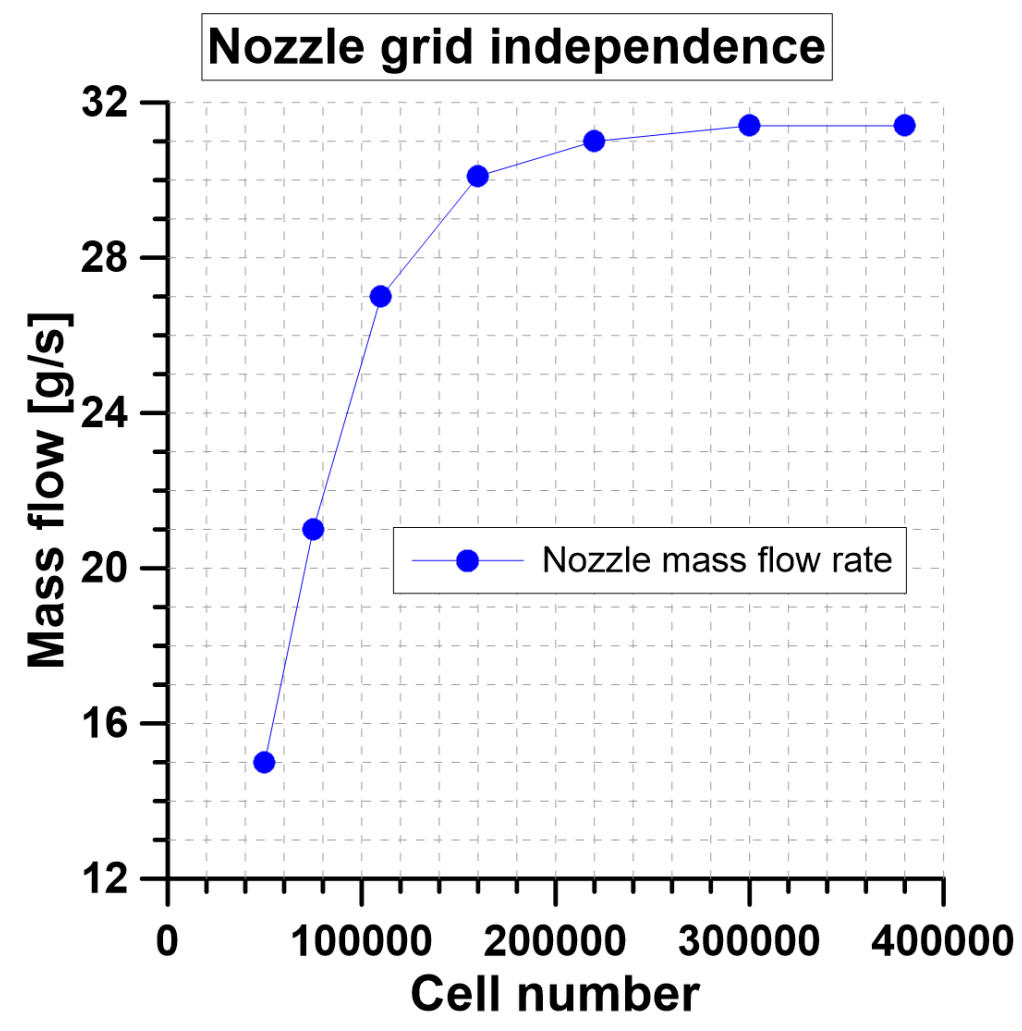

Figure 6. Mass flow rate versus number of cells for the mesh sensitivity study.

It can be seen how the mass flow rate asymptotically tends to a maximum value $(\sim 31.4$ $\mathrm{g} / \mathrm{s})$. The grid convergence indicators (GCI) [40] for the three finest meshes result in $G C I_{21}=0.15 \%$ and $G C I_{32}=0.65 \%$ while the Richardson extrapolation is computed with a value of $31.38 \mathrm{~g} / \mathrm{s}$. Thus, a small discretization error is expected. Respecting both the computational cost and the quality criterion a committed mesh of 238567 cells inside the asymptotic solution range has been chosen for the nozzle. In the case of the calibrated $\mathrm{OZ}$ orifice a total of 162846 elements generate the wedge geometry $\left(5^{\circ}\right)$ and, therefore, 4.48 Mcells for the whole 3D geometry $\left(360^{\circ}\right)$. A high resolution scheme has been used in order to solve the discretized equations.

Using the previously determined mesh characteristics, all cases have been run on six cores of an Intel Core i7-4700HQ $2.40 \mathrm{GHz}$ eight-core processor. A steady-state solver was 
selected, using two main convergence criteria: first, all the residuals must be below $10^{-5}$; additionally, the average velocity and temperature must reach steady conditions.

Regarding the nozzle orifices, the main difference is related to the fact that the nozzle geometry is not axisymmetric. Consequently, the simulations have been performed for a $51.43^{\circ}$ sector representing one of the seven orifices included in the nozzle. This allows to achieve a reasonably consistent prediction of the main flow features at a reduced computational cost compared to a calculation of the complete $360^{\circ}$ geometry. Nevertheless, when comparing to the experiments it has to be considered that, in reality, some orifice-to-orifice dispersion is always present due to small geometrical differences linked to the manufacturing tolerances. This fact may influence the injection characteristics to some extent, as explored by the authors by means of 1D modelling [42] in the case of the orifice diameter and discharge coefficient, among other parameters. Some potential non-uniformities in the needle position and the nozzle flow pattern, including those due to the needle eccentricity, have also been reported in the literature [43]. In any case, symmetry is considered as a reference in this study in order to make this study independent from the influence of the aforementioned manufacturing tolerances on the analyzed thermal effects.

The same modeling methodology and boundary conditions previously explained for the calibrated orifice simulation have been also considered for the nozzle orifice.

\section{Calibrated OZ orifice calculation}

In a previous publication by the authors [21], as previously stated, the temperature variation across a calibrated orifice was measured for a set of boundary conditions in terms of upstream and downstream conditions. These results are used in this section to validate the CFD methodology described in section 3. 
Figure 7 shows the simulation results in terms of the mass flow through the orifice. On the left hand side, this mass flow is plotted against the square root of the pressure drop, defined as the difference between the upstream and downstream pressures ( $p_{u p}$ and $\left.p_{d w}\right)$. Observing the curves, the mass flow rate increases linearly with the square root of the pressure drop. This means that no cavitation appears inside the orifice, as it was expected considering the high conicity factor present in the orifice [8]. Under these conditions, the mass flow inside the orifice is ruled by the following equation:

$$
\dot{m}_{f}=C_{d} \rho_{f} A_{0} u_{o u t}=C_{d} A_{0} \sqrt{2\left(p_{u p}-p_{d w}\right) \rho_{f}}
$$

where $C_{d}$ is the orifice discharge coefficient, $A_{o}$ the geometrical outlet section of the orifice and $u_{\text {out }}$ the outlet velocity, calculated from Bernoulli's equation.

The graph in the right hand side of Figure 7 represents the relative error committed with the numerical approach, defined as the difference among the computed and experimental values divided by the experimental mass flow. It can be observed that below a value of 2 $\mathrm{MPa}^{0.5}$ the relative error is very low, confirming the capability of the current simulation approach to reproduce the main flow characteristics. 

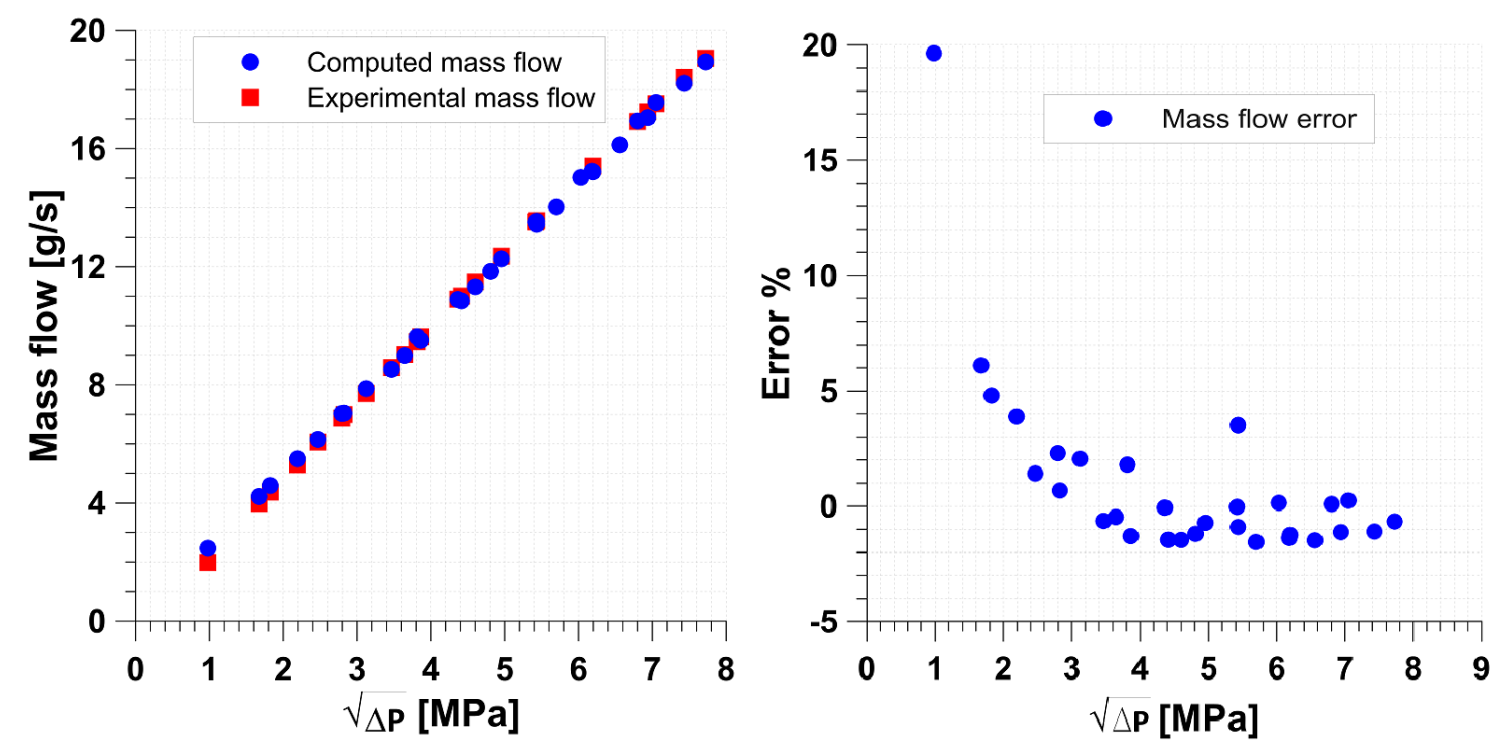

Figure 7. Experimental (from [21]) and computed mass flow (calibrated OZ orifice) as a function of pressure drop from experiments and computed (left). Deviation between experiments and simulations results (right).

Figure 8 shows the results in terms of the outlet temperature. In the left hand side, the outlet temperature is represented as a function of the pressure drop. The experimental results (squares) show the temperature measured by a thermocouple placed downstream of the orifice, according to the experimental arrangement described in [21]. The computational values (circles) show the numerical results of the average temperature in the section where the thermocouple is located. The data show that the outlet temperature tends to increase linearly with the pressure drop, mainly as a consequence of the heating effect produced by the relative friction between the fluid and the orifice walls. Computational results are well aligned with the experiments, with a maximum underprediction of up to approximately $3 \mathrm{~K}$ for the $60 \mathrm{MPa}$ case. The accuracy of the predictions can be better seen in the chart present in the right hand side of that figure, where the relative error associated to the simulation approach in the outlet temperature is depicted, with a maximum value of approximately $0.9 \%$. 

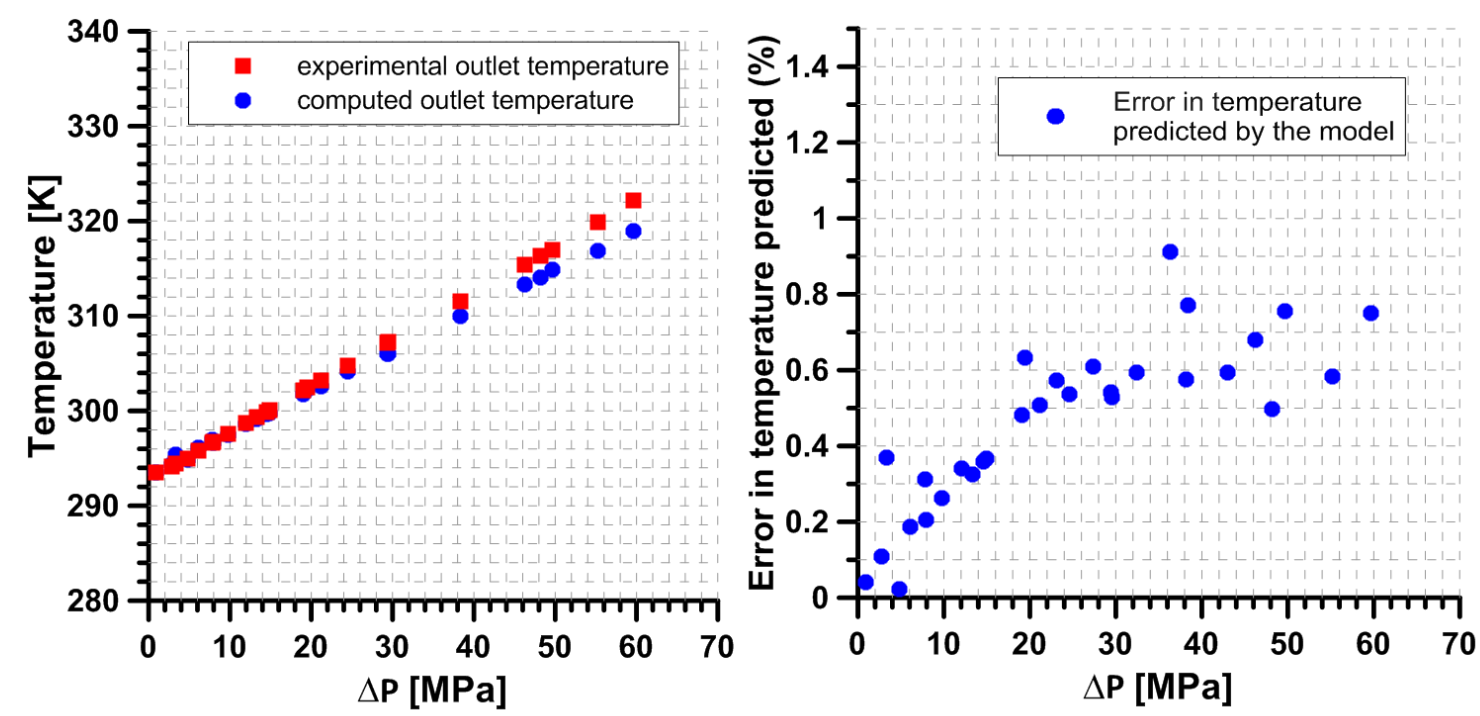

Figure 8. Experimental (from [21]) and computed values of temperature increase as a function of the pressure drop for the calibrated OZ orifice tested (left). Deviation between experiments and simulations (right).

The previous results can also be directly related to the temperature increase along the domain, considering that in all cases the inlet temperature was fixed at $293 \mathrm{~K}$ (equal to the ambient temperature). Thus, the maximum heating produced inside the orifice on the experimental results is approximately $30 \mathrm{~K}$ for an upstream pressure of $60 \mathrm{MPa}$. It has to be noted that this temperature increase could be even more significant when looking at the nozzle orifices of a diesel injector, which are subjected to a much higher pressure drops (and consequently higher velocities). For example, for a $200 \mathrm{MPa}$ injection pressure case (typical for commercial diesel injector nozzles), if the linear trend previously observed were maintained, it would lead to an overall temperature increase of approximately $80 \mathrm{~K}$. This increase can affect the fuel properties at the nozzle outlet, influencing the spray formation processes, so it may need to be considered for spray simulation activities. The heating effects on the nozzle orifices will be further analyzed in Section 5 for a specific diesel nozzle geometry. 
While the average value of the temperature tends to increase, the computational results show that the depressurization in the core of the flow induces a local cooling effect in this region. This behavior can be better seen in Figure 9, where the minimum local temperature in the domain is represented against the pressure drop. For low pressure values, the effect of this depressurization is negligible and the minimum temperature in the domain is approximately equal to the inlet temperature. Starting from approximately a pressure drop value of $10 \mathrm{MPa}$, the minimum temperature starts to drop, reaching a value of approximately $280 \mathrm{~K}$ for the $60 \mathrm{MPa}$ condition, which is in contrast with the average temperature value of $319 \mathrm{~K}$ computed in the outlet section for this particular condition.

The non-uniform distribution of the temperature achieved inside the injector orifices may be of relevance for spray atomization simulations, for instance, especially due to the fact that the fuel viscosity is very sensitive to the temperature in this particular range of temperatures. In addition, the cooling effect may be more significant for the diesel nozzle orifices, since a stronger depressurization would be achieved. This fact will also be analyzed in Section 5 . 


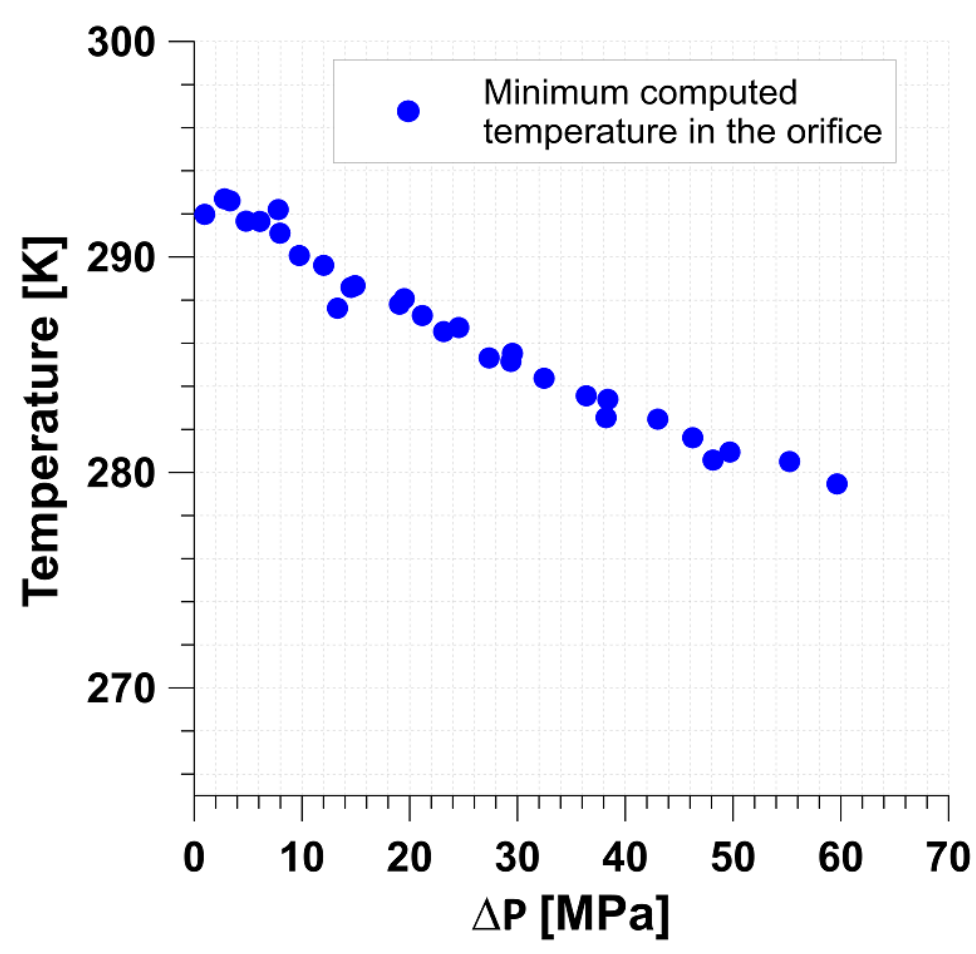

Figure 9. Minimum temperature computed in the whole domain.

A detail of the temperature distribution inside the orifice is provided in Figure 10 for a 60 $\mathrm{MPa}$ upstream pressure and $5 \mathrm{MPa}$ downstream pressure case. In this figure, the flow would go from right (upstream pressure) to left (orifice outlet). Two different behaviors can be observed. On the one hand, the core of the flow suffers a decrease in temperature from $293 \mathrm{~K}$ to approximately $280.5 \mathrm{~K}$. This decrease, as previously mentioned, is related to the transition from high pressure $(60 \mathrm{MPa})$ to low pressure $(5 \mathrm{MPa})$ along the orifice length, coupled to a local increase of the velocity. On the other hand, it can be seen how the temperature tends to increase when moving from the axis to the orifice walls, due to the friction-induced heating effect. Consequently, maximum temperatures of around 315 $\mathrm{K}$ are reached inside the orifice for this particular condition. The final value of outlet temperature previously seen in Figure 7 is a consequence of the combined influence of both effects: cooling in the core flow and heating around the walls. In the case of the geometry studied, the impact of the wall heating is more significant than the one of the 
core flow cooling, leading to an overall temperature increase. Nevertheless, it has to be noted that a different geometry characterized by a different discharge coefficient (and consequently different amount of friction losses) could vary the balance between the two terms, and thus the outlet temperature behavior.

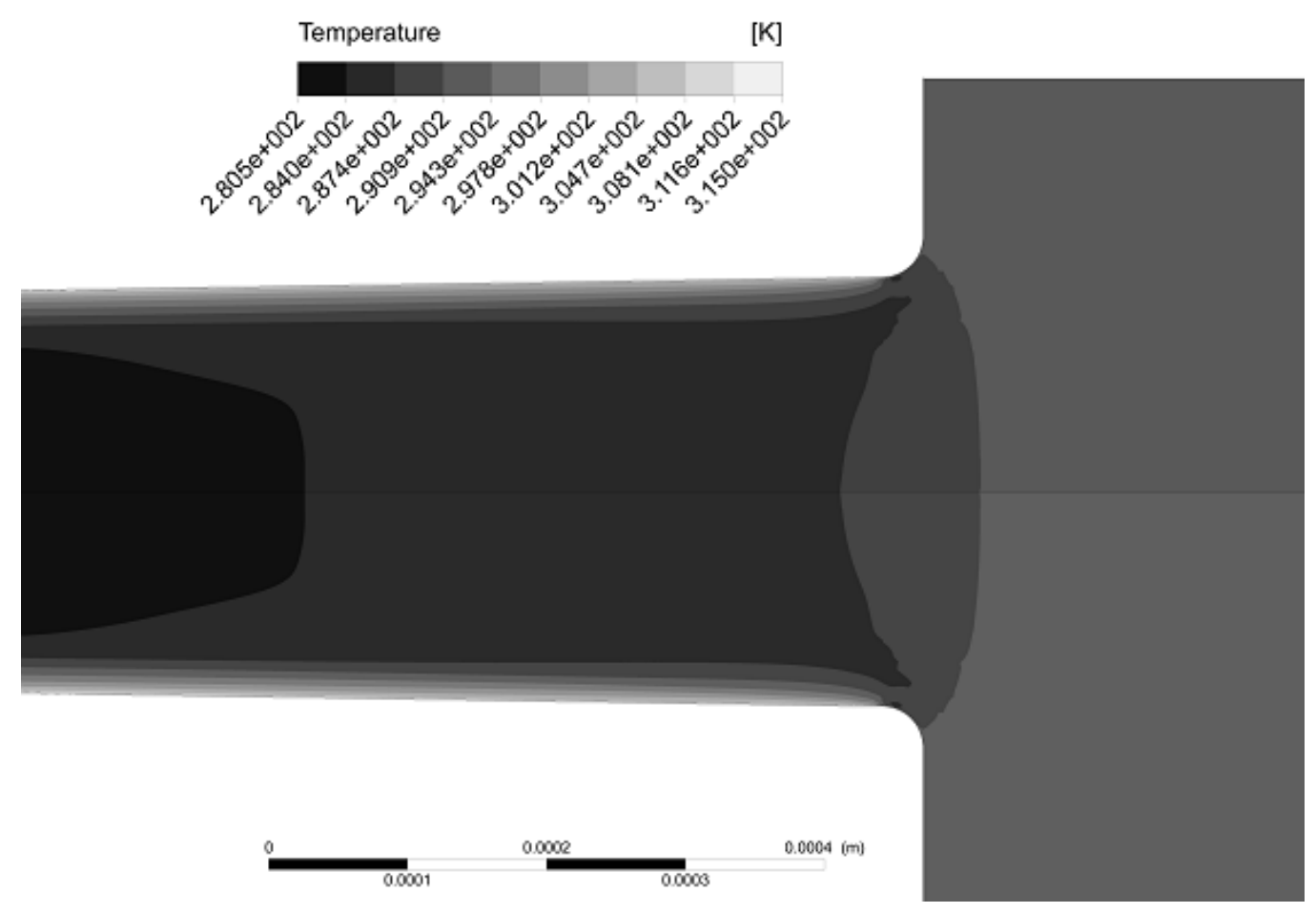

Figure 10. Contour of temperature variations in the calibrated orifice (OZ) for the pressure drop $60 \mathrm{MPa}-5 \mathrm{MPa}$.

Figure 11 shows a detail of the temperature distribution at the orifice outlet section for the same case presented in Figure 10. Since the flow is fully axisymmetric, this temperature distribution appears as a set of concentric rings. It can also be easily seen how most of the temperature gradient is observed close to the orifice walls, while up to approximately two thirds of the orifice radius the temperature ranges from 287.5 to 280.5 K. 


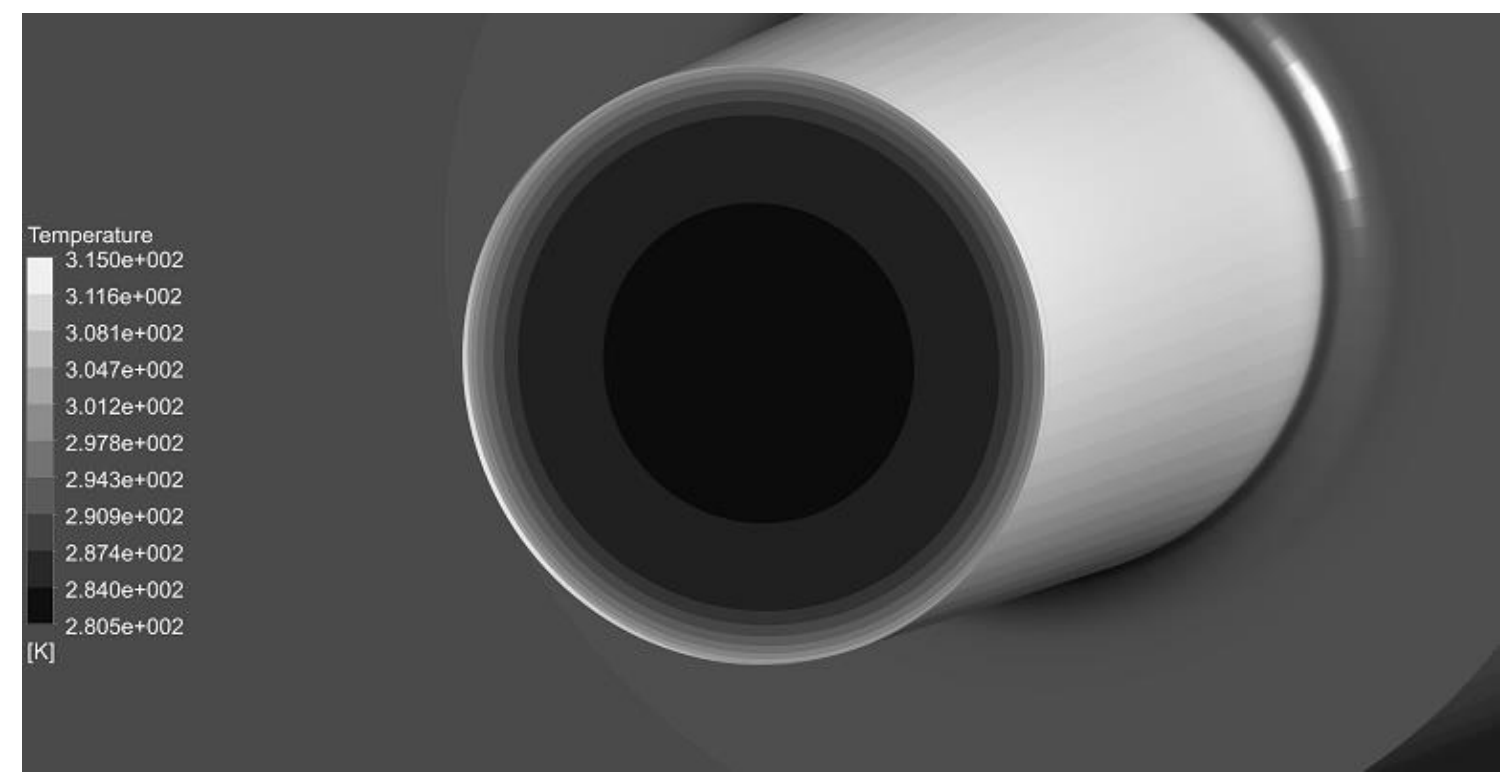

Figure 11. Detail of temperature distribution in the calibrated orifice (OZ) outlet section for the pressure drop $60 \mathrm{MPa}-5 \mathrm{MPa}$.

Figure 12 shows a detail of the distributions of density, pressure, velocity and viscosity around the orifice section. As it can be seen, when the flow enters the orifice (moving from right to left) a small recirculation zone associated to a low pressure region is created around the orifice walls. Nevertheless, the extension of this region is reduced thanks to the combination of the inlet rounding radii and the tapered shape. In the core of the flow, the pressure transitions rapidly from the upstream $(60 \mathrm{MPa})$ to the downstream pressure (5 MPa). Associated to the pressure decrease, the flow velocity also increases in the core flow. Nevertheless, the effect of the friction creates a layer of relatively low velocity around the orifice walls.

In the case of the density distribution, two different phenomena can be observed. On the one hand, there is a trend to reduce the fuel density when passing through the orifice, which is especially visible when comparing the density upstream and inside the orifice. This is associated to the higher-pressure values previously observed upstream the orifice. On the other hand, it can be observed that inside the orifice lower density values are 
achieved around the walls compared to the center of the flow. This is associated to the non-uniform temperature distribution previously commented, which tends to produce higher temperature values around the walls (due to friction-induced heating) and lower values in the core (induced by the depressurization). Regarding the fuel dynamic viscosity, the influence of the fuel pressure in the range $0-60 \mathrm{MPa}$ is low, so only the temperature influence can be noticed.
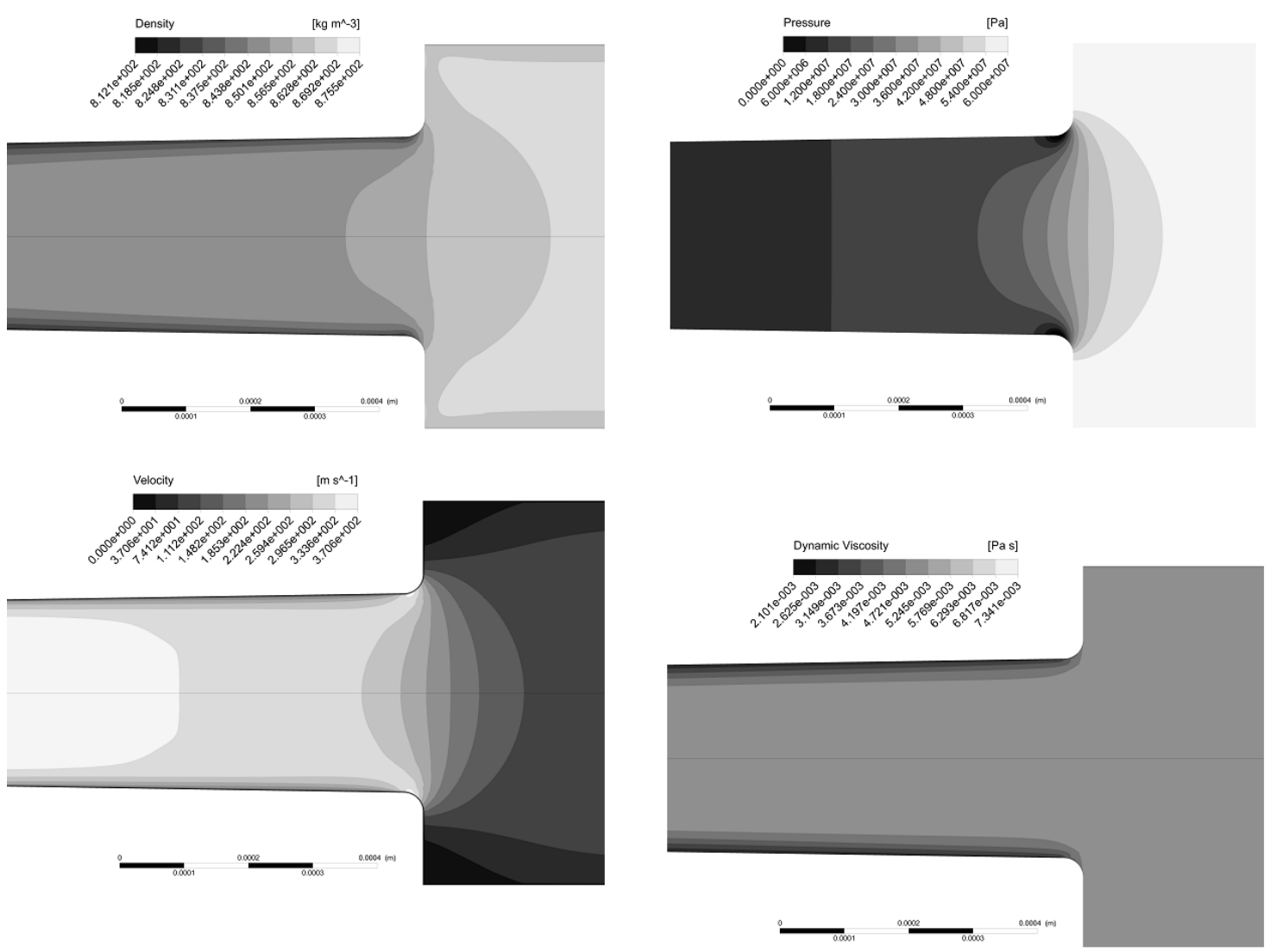

Figure 12. Contours of density, pressure, velocity and dynamic viscosity variations in the calibrated orifice (OZ) for the pressure drop $60 \mathrm{MPa}-5 \mathrm{MPa}$. 


\section{Nozzle orifice calculation}

Figure 13 shows the validation of the nozzle flow simulations in terms of outlet mass flow. The experimental values had been previously obtained using a rate of injection meter, with the methodology described in previous publications by the authors [44]. As it is appreciable, the computational results follow the linear trend of mass flow with respect to the square root of the pressure drop along the nozzle that appears in the experiments. Nevertheless, some overprediction is observed in the computations. On the one hand, it has to be considered that the simulations have been performed introducing an inlet pressure boundary condition in the needle seat region with a pressure value equal to the common-rail pressure, while in reality some pressure drop would occur between these two sections. On the other hand, in reality there is some non-uniformity in the flow produced by each nozzle orifice, which is not captured with the current setup. Additionally, there are some uncertainties in geometrical parameters such as the inlet rounding radii or the orifice surface finish, which could impact in some way the nozzle outlet velocity and mass flow estimations [45]. In any case, differences between experimental and computational mass flow values are within typical ranges in the literature for this kind of simulations. 


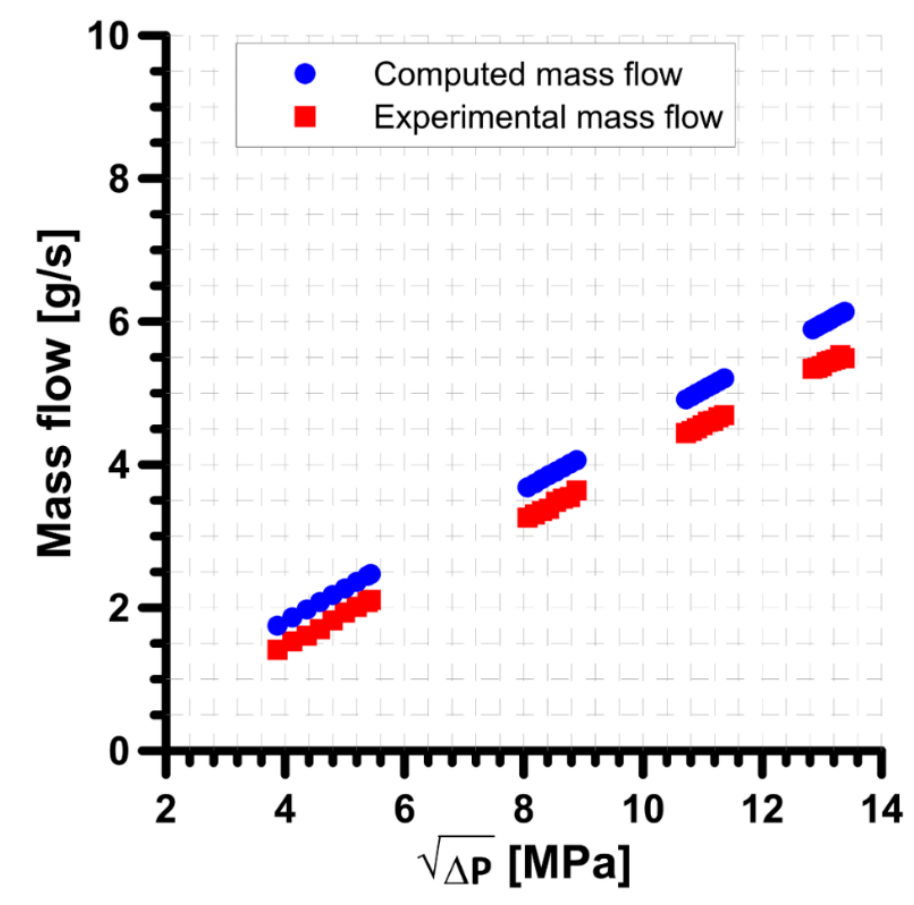

Figure 13: Mass flow validation for nozzle orifice simulations

Figure 14 shows some figures of the thermal behavior inside the orifice as a function of the pressure drop along the nozzle. The ' $\mathrm{x}$ ' symbols represent the maximum local temperature values at the nozzle orifice outlet, which correspond to the area near the orifice walls. As it can be seen, the high pressure drop characteristic of the nozzle orifice leads to a strong friction-induced heating effect in this region (up to $50 \mathrm{~K}$ in the most extreme pressure drop case). On the contrary, the triangles show the minimum temperature values in this same outlet section, linked to the subcooling effect in the core flow. In this area, the temperature can go as low as $260 \mathrm{~K}$, representing approximately a $33 \mathrm{~K}$ temperature decrease. As a consequence, for the $200 \mathrm{MPa}$ injection conditions, there are local differences inside the nozzle outlet section of up to $85 \mathrm{~K}$, which can significantly affect the fuel properties and the spray characteristics. Finally, the circles show the average temperature at the nozzle outlet. While in the OZ calibrated orifice it could be seen that the heating effect in the walls was more significant than the subcooling in the core, always leading to a temperature increase along the domain, in the case of the nozzle 
orifice the opposite trend is found. This is probably linked to the high discharge coefficient of the particular nozzle geometry used for this study, characterized by a combination of high degree of conicity and high inlet rounding radii. As a consequence, the average temperature drops up to a value of $275 \mathrm{~K}$ for the $200 \mathrm{MPa}$ injection pressure conditions.

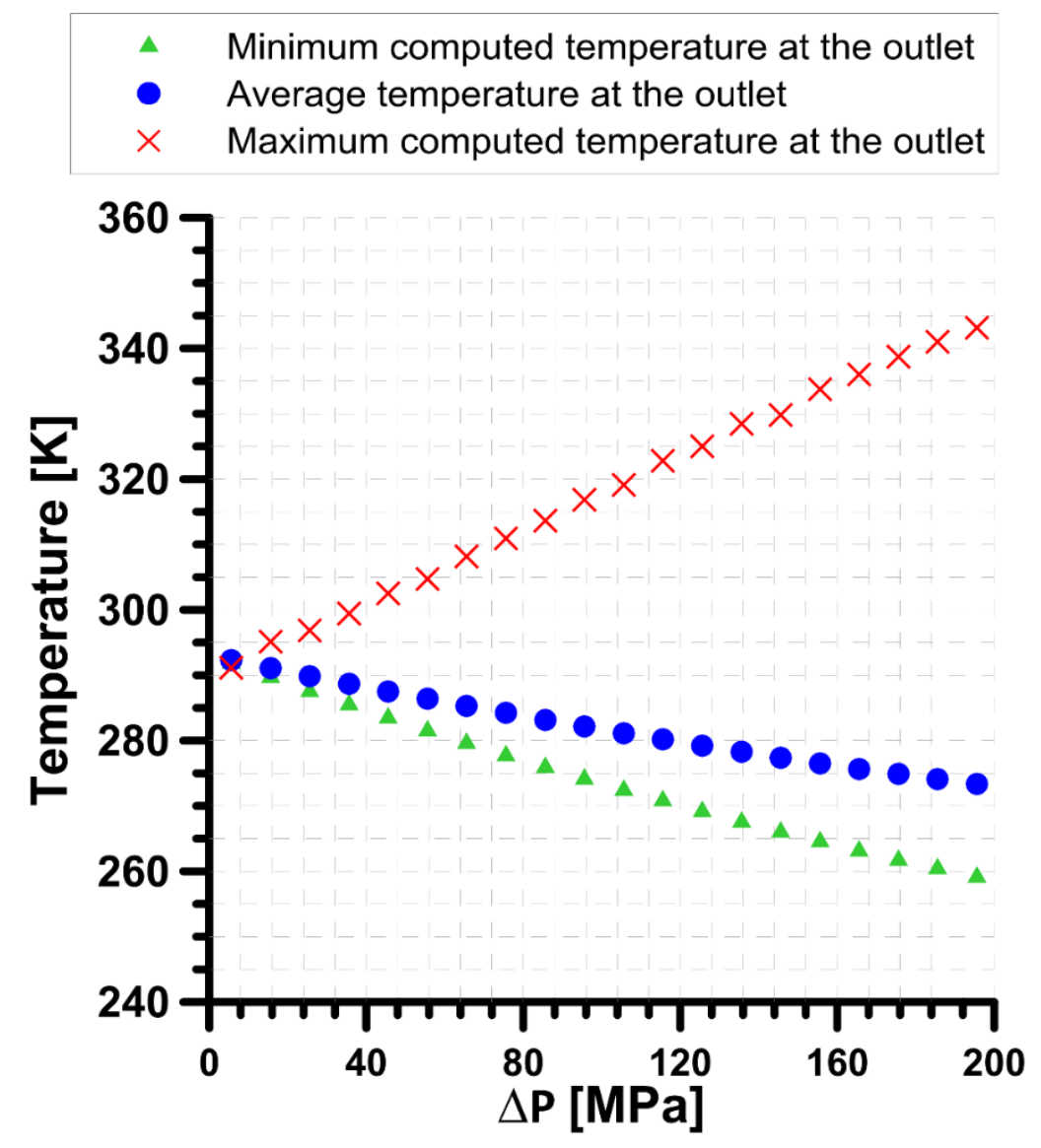

Figure 14: Computed maximum, minimum and average temperatures in the nozzle outlet section as a function of the pressure drop

Figure 15 represents the contours of the temperature distribution inside the orifice. On the left hand side, the temperature contour in the middle plane of the computational domain is depicted. In the inlet part of the orifice (corresponding to the rounding radii region), it can be seen how the temperature drops in the upper side as a consequence of the flow 
detachment and local low pressure values achieved. Once the flow starts to reorganize, the behavior becomes more similar to what was previously observed for the $\mathrm{OZ}$ orifice: a high temperature area appears near the walls due to the friction-heating effect, while the core flow reaches low temperature values due to the depressurization. Nevertheless, it can be noticed that the high temperature area is wider in the upper side. Consequently, the temperature distribution in the outlet section (seen in the right hand side of the figure) shows a deformation for the iso-temperature curves in this upper side, inducing most of the low-temperature area to be located near the lateral walls. As it can also be seen in this figure, a similar behavior is also achieved in the bottom side of the orifice, but to a much lower extent.

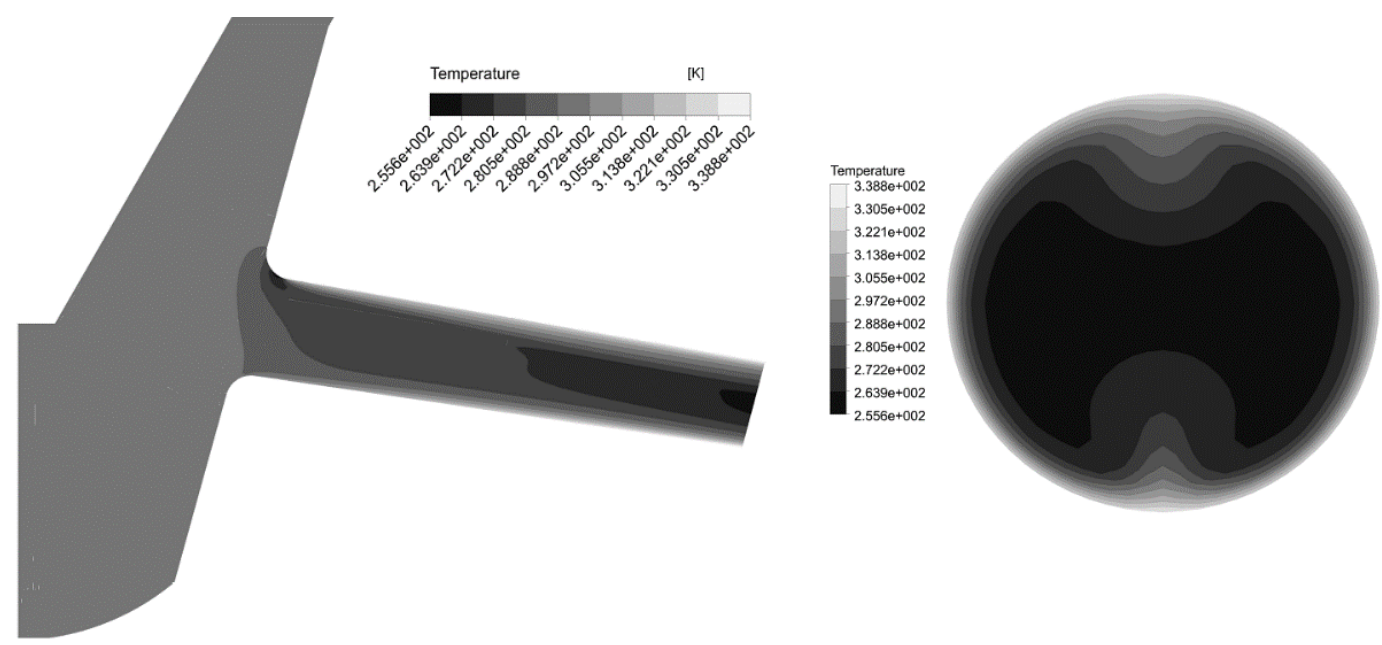

Figure 15: Temperature distribution contours inside the nozzle geometry, for a middle plane of the domain (left) and the outlet section (right).

This non-symmetric distribution of temperature can be better understood looking at the information depicted in Figure 16. In this figure, the local temperature contours are superimposed with streamlines reproducing the direction of the flow path. As it can be seen, most of the streamlines reaching the orifice are originated in the needle seat region. Thus, higher local velocities are reached in this region, producing a stronger friction- 
heating effect and higher local temperatures compared to the lateral sides. Something similar appears in the bottom side of the orifice, where some of the streamlines appear from the lowest portion of the sac volume, inducing also an extension of the high temperature zone.
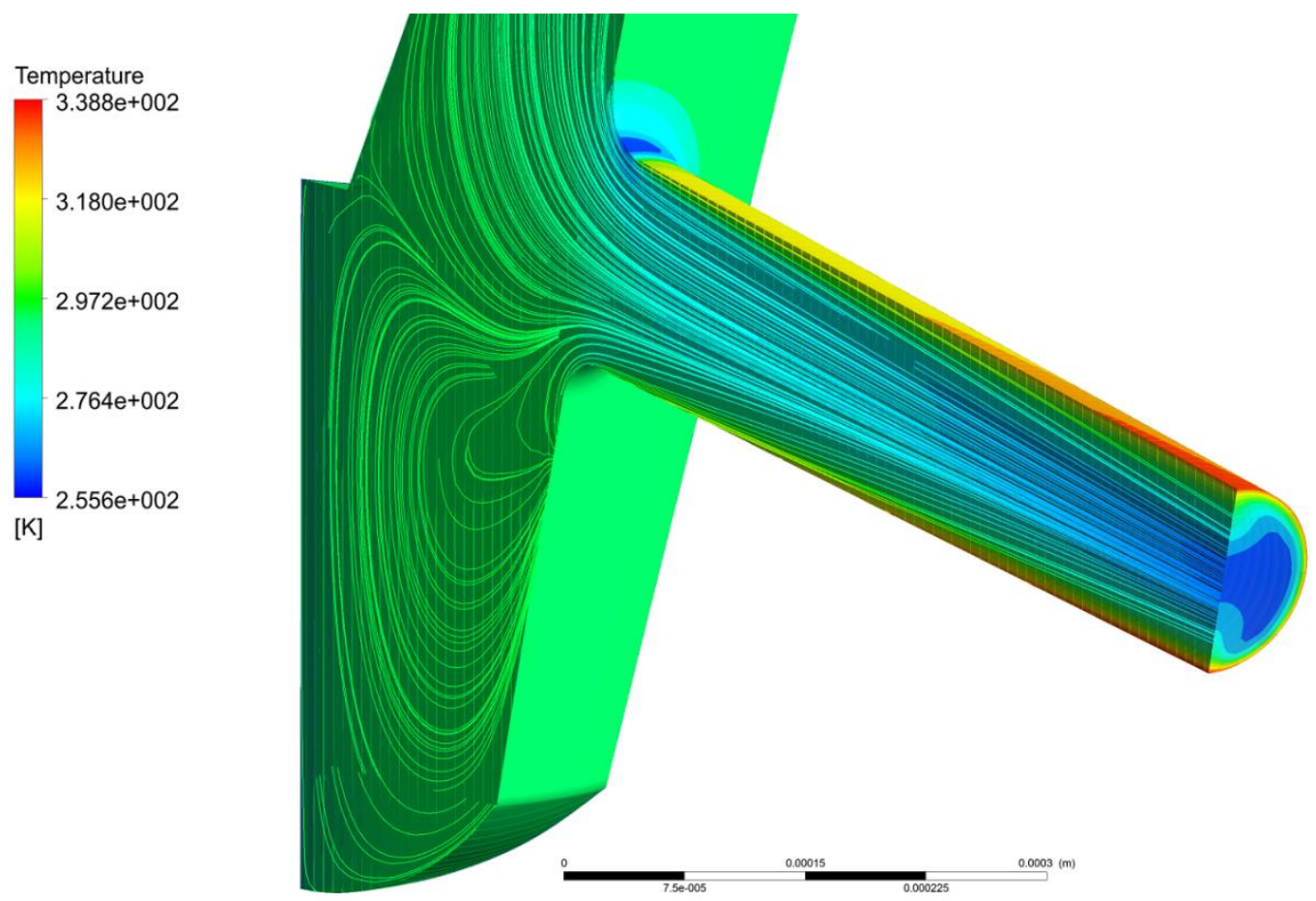

Figure 16: Combination of flow streamlines and temperature contours for the nozzle orifice

\section{Conclusions}

In the current paper, a modeling methodology has been proposed in order to evaluate the thermal aspects involved inside diesel injectors through CFD simulations. This methodology is based on an adiabatic flow condition, which is considered reasonable due to the high flow velocities characteristic of the diesel injection process. Additionally, the dependencies of the most important fuel properties (density, viscosity, thermal conductivity and heat capacity) as a function of pressure and temperature have been incorporated into the CFD code by means of user-defined functions. This methodology 
has shown a very good capability to reproduce the experimental outlet temperature on a calibrated orifice, with a maximum deviation of approximately $0.9 \%$ with respect to the experimental tests. Additionally, the CFD approach has been validated also in terms of the mass flow behavior. Nevertheless, it has to be noted that no experimental validation of the temperature spatial distribution could be performed, given the small dimensions characterizing the orifices of study.

A detailed analysis of this temperature distribution in the orifice has shown that in reality there are two counter-acting phenomena occurring inside the orifice. On the one hand, there is a friction-induced heating near the walls, as previously anticipated. On the other hand, the core flow is generally subjected to a depressurization, associated to a decrease in the local temperature. In the case of the control volume calibrated orifice, this second effect is less significant compared to the friction-induced heating, producing a net temperature increase.

Once the modeling methodology has been validated for the calibrated orifice, the same kind of analysis has been extended for a diesel nozzle orifice. The interest of this orifice is linked to its much higher pressure drop, which is expected to induce stronger thermal effects, and the impact that this different temperature behavior could have on the atomization and spray formation processes. For this purpose, a commercial 7-holes solenoid injector has been geometrically characterized in order to obtain information to construct the 3D model for the internal flow simulations.

The results for the nozzle orifices show again a separated behavior between the walls and the core of the flow. For an injection pressure of $200 \mathrm{MPa}$, the difference between the local maximum and minimum temperatures in the outlet section is around $83 \mathrm{~K}$, which would induce significant differences in terms of the fuel physical properties, which in 
turn may be relevant for atomization and spray formation processes. Additionally, it can be seen how the non-uniform distribution of the flow inside the nozzle, induced mostly by the flow bending from the needle seat region to the orifice, produces also a nonsymmetric temperature distribution in the outlet orifice.

\section{REFERENCES}

[1] A. Nigro, A. Algieri, C. De Bartolo, and S. Bova, "Fluid dynamic investigation of innovative intake strategies for multivalve internal combustion engines," Int. J. Mech. Sci., vol. 123, no. February, pp. 297-310, 2017.

[2] B. Mohan, W. Yang, and S. K. Chou, "Fuel injection strategies for performance improvement and emissions reduction in compression ignition engines - A review," Renew. Sustain. Energy Rev., vol. 28, no. x, pp. 664-676, 2013.

[3] S. Som, A. I. Ramírez, D. E. Longman, and S. K. Aggarwal, "Effect of nozzle orifice geometry on spray, combustion, and emission characteristics under diesel engine conditions," Fuel, vol. 90, no. 3, pp. 1267-1276, 2011.

[4] C. Sayin, M. Gumus, and M. Canakci, "Influence of injector hole number on the performance and emissions of a di diesel engine fueled with biodiesel-diesel fuel blends," Appl. Therm. Eng., vol. 61, no. 2, pp. 121-128, 2013.

[5] M. Gavaises, "Flow in valve covered orifice nozzles with cylindrical and tapered holes and link to cavitation erosion and engine exhaust emissions," Int. J. Engine Res., vol. 9, no. 6, pp. 435-447, 2008.

[6] F. J. Salvador, M. Carreres, D. Jaramillo, and J. Martínez-lópez, “Analysis of the combined effect of hydrogrinding process and inclination angle on hydraulic performance of diesel injection nozzles," 
Energy Convers. Manag., vol. 105, pp. 1352-1365, 2015.

[7] S. Molina, F. J. Salvador, M. Carreres, and D. Jaramillo, “A computational investigation on the influence of the use of elliptical orifices on the inner nozzle flow and cavitation development in diesel injector nozzles," Energy Convers. Manag., vol. 79, pp. 114-127, 2014.

[8] F. J. Salvador, J. de la Morena, M. Carreres, and D. Jaramillo, "Numerical analysis of flow characteristics in diesel injector nozzles with convergent-divergent orifices," Proc. Inst. Mech. Eng. Part D J. Automob. Eng., vol. In press, Feb. 2017.

[9] D. Nguyen et al., "Spray flow structure from twin-hole diesel injector nozzles," Exp. Therm. Fluid Sci., vol. 86, pp. 235-247, 2017.

[10] X. Wang, Z. Huang, W. Zhang, O. A. Kuti, and K. Nishida, "Effects of ultra-high injection pressure and micro-hole nozzle on flame structure and soot formation of impinging diesel spray," Appl. Energy, vol. 88, no. 5, pp. 1620-1628, 2011.

[11] M. Gumus, C. Sayin, and M. Canakci, "The impact of fuel injection pressure on the exhaust emissions of a direct injection diesel engine fueled with biodiesel-diesel fuel blends," Fuel, vol. 95, no. 1, pp. 486-494, May 2012.

[12] E. Giannadakis, M. Gavaises, and A. Theodorakakos, “The influence of variable fuel properties in highpressure diesel injectors," SAE Tech. Pap. 2009-01-0832, 2009.

[13] S. Som, D. E. Longman, A. I. Ramírez, and S. K. Aggarwal, “A comparison of injector flow and spray characteristics of biodiesel with petrodiesel," Fuel, vol. 89, pp. 4014-4024, 2010.

[14] Z.-Y. Sun, G.-X. Li, C. Chen, Y.-S. Yu, and G.-X. Gao, "Numerical investigation on effects of nozzle's geometric parameters on the flow and the cavitation characteristics within injector's nozzle for a highpressure common-rail DI diesel engine,” Energy Convers. Manag., vol. 89, pp. 843-861, 2015.

[15] M. S. Alam, M. A. Khatun, M. M. Rahman, and K. Vajravelu, "Effects of variable fluid properties and thermophoresis on unsteady forced convective boundary layer flow along a permeable stretching/shrinking wedge with variable Prandtl and Schmidt numbers," Int. J. Mech. Sci., vol. 105, 
pp. 191-205, 2016.

[16] A. E. Catania, A. Ferrari, and E. Spessa, "Temperature variations in the simulation of high-pressure injection-system transient flows under cavitation,” Int. J. Heat Mass Transf., vol. 51, pp. 2090-2107, 2008.

[17] R. Payri, F. J. Salvador, M. Carreres, and J. De la Morena, "Fuel temperature influence on the performance of a las generation common-rail diesel ballistic injector. Part II: 1D model development, validation and analysis," Energy Convers. Manag., pp. 1-16, 2016.

[18] J. Shi, N. Guerrassi, G. Dober, K. Karimi, and Y. Meslem, "Complex physics modelling of diesel injector nozzle flow and spray supported by new experiments," in THIESEL 2014 Conference on Thermo- and Fluid Dynamic Processes in Direct Injection Engines, 2014, pp. 1-21.

[19] A. Theodorakakos, G. Strotos, N. Mitroglou, C. Atkin, and M. Gavaises, "Friction-induced heating in nozzle hole micro-channels under extreme fuel pressurisation," Fuel, vol. 123, no. x, pp. 143-150, 2014.

[20] G. Strotos, P. Koukouvinis, A. Theodorakakos, M. Gavaises, and G. Bergeles, "Transient heating effects in high pressure Diesel injector nozzles,” Int. J. Heat Fluid Flow, vol. 51, pp. 257-267, 2015.

[21] F. J. Salvador, J. Gimeno, M. Carreres, and M. Crialesi-Esposito, "Experimental assessment of the fuel heating and the validity of the assumption of adiabatic flow through the internal orifices of a diesel injector," Fuel, vol. 188, pp. 442-451, 2017.

[22] F. J. Salvador, J. Gimeno, J. De la Morena, and M. Carreres, "Using one-dimensional modeling to analyze the influence of the use of biodiesels on the dynamic behavior of solenoid-operated injectors in common rail systems: Results of the simulations and discussion," Energy Convers. Manag., vol. 54, no. 1 , pp. 122-132, 2012.

[23] V. Macian, V. Bermúdez, R. Payri, and J. Gimeno, "New technique for determination of internal geometry of a Diesel nozzle with the use of silicone methodology," Exp. Tech., vol. 27, no. April, pp. 39-43, 2003.

[24] F. J. Salvador, J. Gimeno, J. De la Morena, and M. Carreres, "Comparison of Different Techniques for 
Characterizing the Diesel Injector Internal Dimensions,” Exp. Tech., In press, doi: 10.1007/s40799018-0246-1, 2018.

[25] R. Payri, F. J. Salvador, J. Gimeno, and R. Novella, "Flow regime effects on non-cavitating injection nozzles over spray behavior," Int. J. Heat Fluid Flow, vol. 32, no. 1, pp. 273-284, 2010.

[26] F. Payri, V. Bermúdez, R. Payri, and F. J. Salvador, "The influence of cavitation on the internal flow and the spray characteristics in diesel injection nozzles," Fuel, vol. 83, no. 4-5, pp. 419-431, 2004.

[27] F. J. Salvador, S. Hoyas, R. Novella, and J. Martínez-López, "Numerical simulation and extended validation of two-phase compressible flow in diesel injector nozzles," Proc. Inst. Mech. Eng. Part D J. Automob. Eng., vol. 225, no. 4, pp. 545-563, 2011.

[28] F. J. Salvador, J. Martínez-López, J. V. Romero, and M. D. Roselló, “Computational study of the cavitation phenomenon and its interaction with the turbulence developed in diesel injector nozzles by Large Eddy Simulation (LES),” Math. Comput. Model., vol. 57, no. 7-8, pp. 1656-1662, 2013.

[29] F. J. Salvador, J. De la Morena, J. Martínez-López, and D. Jaramillo, “Assessment of compressibility effects on internal nozzle flow in diesel injectors at very high injection pressures," Energy Convers. Manag., vol. 132, pp. 221-230, 2017.

[30] “ASTM D1298-12b, Standard Test Method for Density, Relative Density, or API Gravity of Crude Petroleum and Liquid Petroleum Products by Hydrometer Method.” West Conshohocken, PA, 2012.

[31] J. M. Desantes, F. J. Salvador, M. Carreres, and D. Jaramillo, "Experimental Characterization of the Thermodynamic Properties of Diesel Fuels Over a Wide Range of Pressures and Temperatures," SAE Int. J. Fuels Lubr., vol. 8, no. 1, pp. 2015-01-0951, 2015.

[32] “ASTM D445-15a, Standard Test Method for Kinematic Viscosity of Transparent and Opaque Liquids (and Calculation of Dynamic Viscosity).”ASTM International, West Conshohocken, PA, 2015.

[33] B. Kouzel, "How pressure affects liquid viscosity," Hydrocarb. Process. Pet. Refin., vol. 44 (3), p. 120, 1965. 
[34] N. I. Kolev, "Thermodynamic and transport properties of diesel fuel," in Multiphase Flow Dynamics 3: turbulence, gas absorption and release, diesel fuel properties, 3rd editio., Springer Verlag, 2007, pp. 293-327.

[35] W. Jeong and J. Seong, "Comparison of effects on technical variances of computational fluid dynamics (CFD) software based on finite element and finite volume methods," Int. J. Mech. Sci., vol. 78, pp. 19$26,2014$.

[36] V. Yakhot and S. Orszag, "Renormalization group analysis of turbulence. basic theory," J. Sci. Comput., vol. 1, no. 1, pp. 3-51, 1986.

[37] R. Castilla, P. J. Gamez-Montero, N. Ertrk, A. Vernet, M. Coussirat, and E. Codina, "Numerical simulation of turbulent flow in the suction chamber of a gearpump using deforming mesh and mesh replacement," Int. J. Mech. Sci., vol. 52, no. 10, pp. 1334-1342, 2010.

[38] F. J. Salvador, M. Carreres, D. Jaramillo, and J. Martínez-López, “Comparison of microsac and VCO diesel injector nozzles in terms of internal nozzle flow characteristics," Energy Convers. Manag., vol. 103, pp. 284-299, 2015.

[39] “Ansys-CFX-solver theory guide, release 15.0,” 2013.

[40] P. J. Roache, "Perspective: A Method for Uniform Reporting of Grid Refinement Studies," J. Fluids Eng., vol. 116, no. 3, p. 405, 1994.

[41] P. Li, J. Mi, B. B. Dally, R. A. Craig, and F. Wang, "Premixed moderate or intense low-oxygen dilution (MILD) combustion from a single jet burner in a laboratory-scale furnace," Energy and Fuels, vol. 25, no. 7, pp. 2782-2793, 2011.

[42] F. J. Salvador, M. Carreres, M. Crialesi-Esposito, and A. H. Plazas, "Determination of critical operating and geometrical parameters in diesel injectors through one dimensional modelling, design of experiments and an analysis of variance," Proc. Inst. Mech. Eng. Part D J. Automob. Eng., In press, doi: 10.1177/0954407017735262, 2017.

[43] F. J. Salvador, J. Martínez-López, J. V. Romero, and M. D. Roselló, "Study of the influence of the 
needle eccentricity on the internal flow in diesel injector nozzles by computational fluid dynamics calculations," Int. J. Comput. Math., vol. 91, no. June, pp. 24-31, 2013.

[44] R. Payri, F. J. Salvador, J. Gimeno, and G. Bracho, "A new methodology for correcting the signal cumulative phenomenon on injection rate measurements," Exp. Tech., vol. 32, no. February, pp. 46-49, 2008.

[45] Y. Cai, Z. Liu, Q. Song, Z. Shi, and Y. Wan, "Fluid mechanics of internal flow with friction and cutting strategies for micronozzles," Int. J. Mech. Sci., vol. 100, pp. 41-49, 2015. 